NATIONAL LABORATORY

MANAGED BY UT-BATTELLE

FOR THE DEPARTMENT OF ENERGY

\title{
Hygrothermal Simulation of Foundations: Part 1, Soil Material Properties
}

\section{September 2012}

Prepared by

Manfred Kehrer

Simon Pallin

Anna Harmon

Louise F. Goldberg

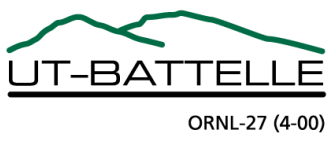




\section{DOCUMENT AVAILABILITY}

Reports produced after January 1, 1996, are generally available free via the U.S. Department of Energy (DOE) Information Bridge.

Web site http://www.osti.gov/bridge

Reports produced before January 1, 1996, may be purchased by members of the public from the following source.

National Technical Information Service

5285 Port Royal Road

Springfield, VA 22161

Telephone 703-605-6000 (1-800-553-6847)

TDD 703-487-4639

Fax 703-605-6900

E-mail info@ntis.gov

Web site http://www.ntis.gov/support/ordernowabout.htm

Reports are available to DOE employees, DOE contractors, Energy Technology Data Exchange (ETDE) representatives, and International Nuclear Information System (INIS) representatives from the following source.

Office of Scientific and Technical Information

P.O. Box 62

Oak Ridge, TN 37831

Telephone 865-576-8401

Fax 865-576-5728

E-mail reports@osti.gov

Web site http://www.osti.gov/contact.html

This report was prepared as an account of work sponsored by an agency of the United States Government. Neither the United States Government nor any agency thereof, nor any of their employees, makes any warranty, express or implied, or assumes any legal liability or responsibility for the accuracy, completeness, or usefulness of any information, apparatus, product, or process disclosed, or represents that its use would not infringe privately owned rights. Reference herein to any specific commercial product, process, or service by trade name, trademark, manufacturer, or otherwise, does not necessarily constitute or imply its endorsement, recommendation, or favoring by the United States Government or any agency thereof. The views and opinions of authors expressed herein do not necessarily state or reflect those of the United States Government or any agency thereof. 
ORNL/TM-2012/289

Building Technologies Research and Integration Center Energy and Transportation Science Division

\title{
Hygrothermal Simulation of Foundations: Part 1, Soil Material Properties
}

\author{
Manfred Kehrer, Sr. R\&D Staff \\ Simon Pallin, Lic Eng* \\ Anna Harmon, $\mathrm{PE} \dagger$ \\ Louise F. Goldberg, $\mathrm{PhD} \dagger$
}

Date Published: September 2012

\footnotetext{
*Building Physics, Division of Building Technology, Department of Civil and Environmental, Chalmers University of Technology, Gothenburg, Sweden

$\dagger$ Energy Systems Design Program, Department of Bioproducts and Biosystems Engineering, University of Minnesota.
}

\author{
Prepared by \\ OAK RIDGE NATIONAL LABORATORY \\ Oak Ridge, Tennessee 37831-6283 \\ managed by \\ UT-BATTELLE, LLC \\ for the \\ U.S. DEPARTMENT OF ENERGY \\ under contract DE-AC05-00OR22725
}





\section{CONTENTS}

\section{Page}

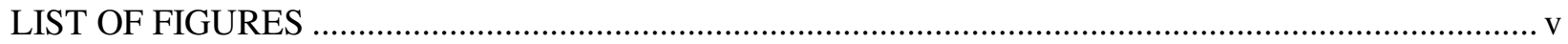

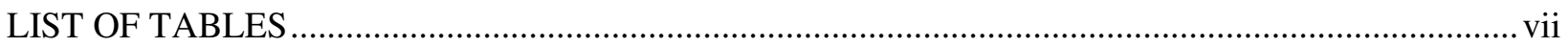

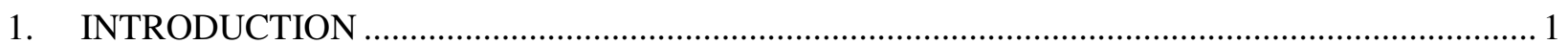

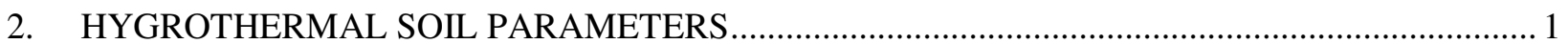

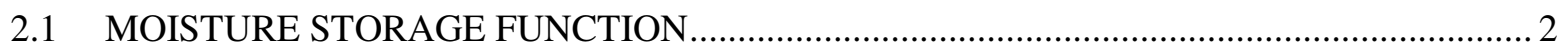

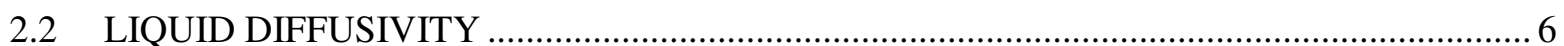

2.3 VAPOR DIFFUSION RESISTANCE FACTOR …....................................................... 7

2.4 DRY BULK DENSITY, PARTICLE DENSITY, AND POROSITY …............................... 7

2.5 THERMAL CONDUCTIVITY AND HEAT CAPACITY …............................................ 8

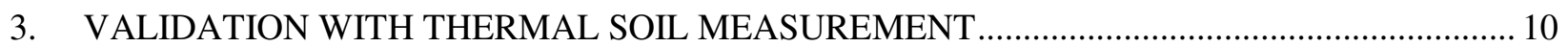

4. FULL BASEMENT WALL HYGROTHERMAL VALIDATION DATA GENERATION

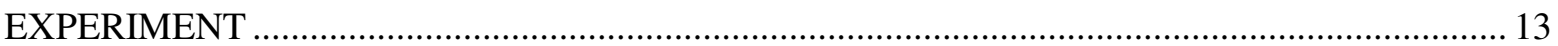

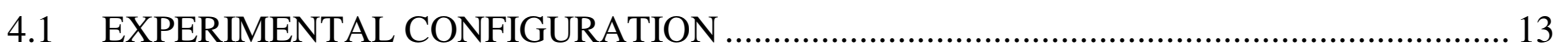

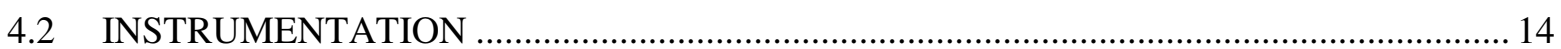

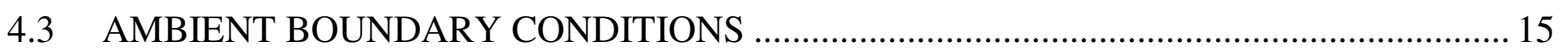

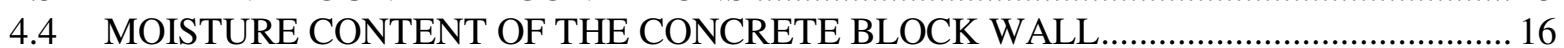

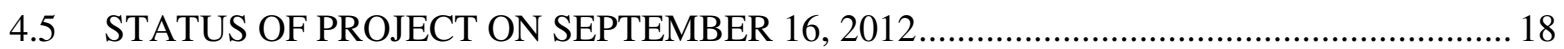

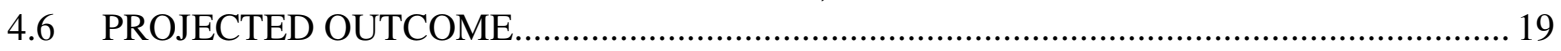

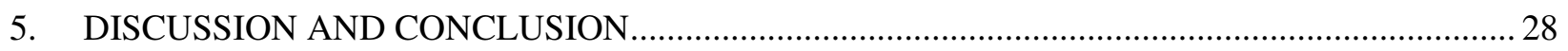

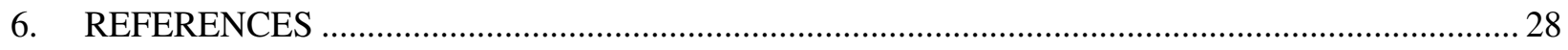

APPENDIX A. Moisture Storage Functions Based on Eq. (11) ........................................................... 32

APPENDIX B. $D_{d r y}$ Values for All Soil Texture Classes and $D_{\text {wet }}$ Values for Clay and Silt.................... 34

APPENDIX C. Soil Thermal Conductivities as a Function of Water Content from Eq. (21) for Clay,

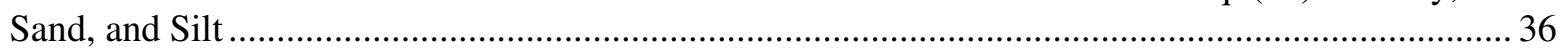

APPENDIX D. Compositions of the 12 USCS Soil Textures and Their Thermal Conductivities ............ 38 



\section{LIST OF FIGURES}

Figure

1. Soil texture triangle representing the 12 classes of soil texture used by the Natural Resources Conservation Service of the US Department of Agriculture

2. Moisture storage function of loam at fixed temperatures of 0 and $20^{\circ} \mathrm{C}$

3. Thermal conductivity for sand, loam, silt, and silty clay as a function of the water content of the soils

4. Simulation model representing one-dimensional and semi-infinite hygrothermal transfer through the ground

5. Comparison between measured and simulated ground temperature at the depth of $1 \mathrm{~m}$ in Holzkirchen, Germany

6. Schematic design of test panels and associated instrumentation ..................................................... 20

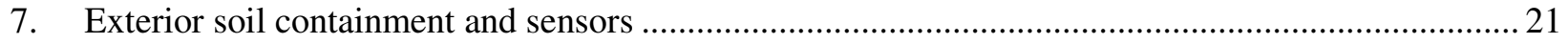

8. Exterior sensors (block moisture content and temperature) ......................................................... 22

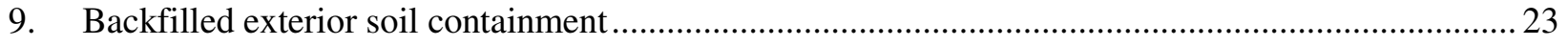

10. Interior block wall sensors (block moisture content, humidity, and temperature)...........................24

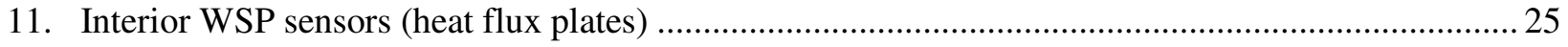

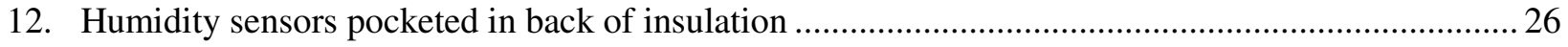

13. Interior face of insulation sensors (humidity and temperature) …................................................. 27 



\section{LIST OF TABLES}

Table

Page

1. Average hydraulic parameters required in Eq. (1) to calculate the saturation effect and in Eq. (13) to calculate the liquid diffusivity 3

2. Dry bulk density, particle density, and porosity for the 12 soil textures where the bulk and particle density are obtained from averages of 560 soil samples

3. Coefficients for clay, sand, and silt (frozen and unfrozen) required to estimate the soil thermal

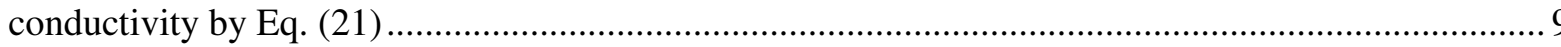

4. Assumed texture compositions of clay, sand, and silt .................................................................. 10

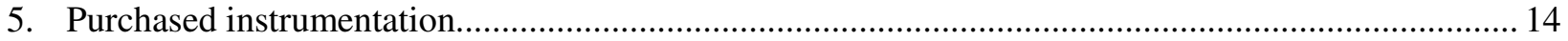





\section{INTRODUCTION}

The hygrothermal performance of soils coupled to buildings is a complicated process. A computational approach for heat transfer through the ground has been well defined (EN ISO 13370:2007, 2007), and simplified methods have been developed (Staszczuk, Radon, and Holm 2010). However, these approaches generally ignore the transfer of soil moisture, which is not negligible (Janssen, Carmeliet, and Hens 2004).

The material properties of soils must be reliable for the performance of realistic hygrothermal calculations of soils coupled to buildings, but such material properties are not well defined in present hygrothermal calculation tools. Typical types of building construction that are greatly influenced by soils are basements, crawl spaces, and slabs on grade. Reliable hygrothermal performance indicators for these constructions are sorely needed; requests for this ranked within the top 10 Building America Enclosure Research Ideas at the Enclosures STC - Residential Energy Efficiency Stakeholder Meeting held February 29, 2012, in Austin, Texas. The Soil Science literature contains an extensive amount of measurements on soil properties, but this information must be gathered as well as adapted for application to hygrothermal simulations in Building Science.

Soil properties are important when analyzing and designing both new buildings and retrofits for which the outer boundary of the building enclosure will consist of soil materials. For basement retrofits aimed at energy efficiency, interior solutions to decrease the energy demand must be designed in consideration to existing soil properties. For exterior retrofits, the soil material can be replaced, if needed, with a more suitable filling material, though this approach applies only to basement walls. The soil material beneath the basement floor obviously cannot be replaced; hence the soil properties of this part of a building enclosure still must be taken into consideration.

This study is divided into several parts. The intention of the first part is to gather, comprehend and adapt soil properties from Soil Science. The obtained information must be applicable to related tasks in Building Science and validated with hygrothermal calculation tools. Future parts of this study will focus on the validation aspect of the soil properties to be implemented. Basic changes in the software code may be requested at this time. Different types of basement construction will be created with a hygrothermal calculation tool, WUFI. Simulations from WUFI will be compared with existing or ongoing measurements.

The final outcome of the study will be the evaluation of several soil types in several climate zones for a number of basement assembly types. The study will define the type of soil, together with the type of building construction, considered most and least reliable with respect to energy consumption and moisture safety. Further, the study will determine (1) the influences that different soils have on total energy loss through the ground and (2) whether the performance of different soils can be measured solely by a comparison of soil properties.

\section{HYGROTHERMAL SOIL PARAMETERS}

Soils can be classified by soil texture. According to the Unified Soil Classification System (USCA), 12 different soils can be defined on the basis of three soil components: clay, sand, and silt (Noorallah 1999). The 12 soil textures in the USCA are presented in the soil texture triangle shown in Fig. 1. This study will define the material properties of these 12 soil types. 


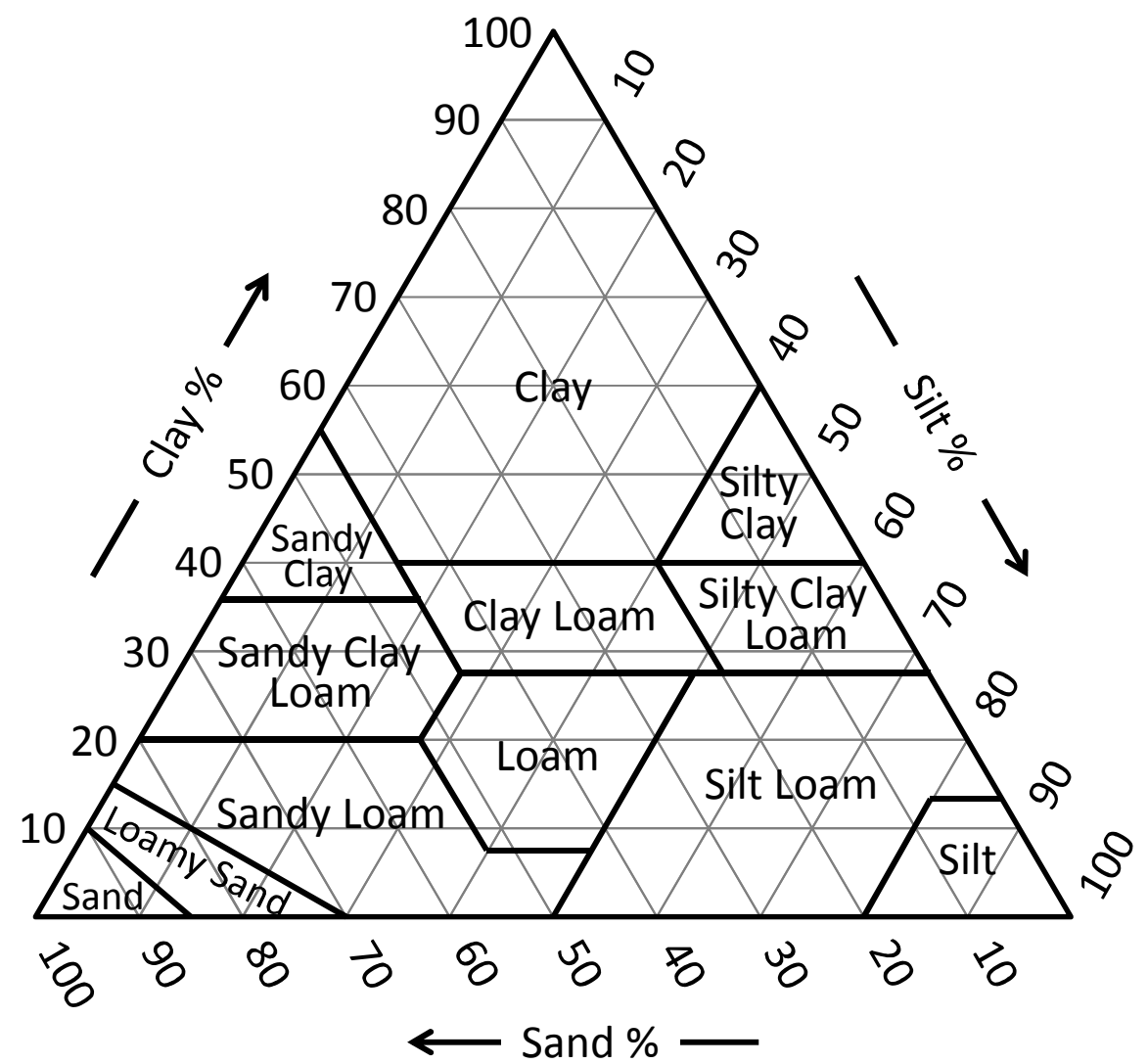

Fig. 1. Soil texture triangle representing the 12 classes of soil texture used by the Natural Resources Conservation Service of the US Department of Agriculture. (Duble 2011, Noorallah 1999)

The soil properties of interest for hygrothermal calculations are

- Dry bulk and particle density

- Porosity

- Thermal conductivity

- Specific heat capacity

- Moisture storage function

- Water liquid diffusivity

- Vapor diffusion resistance factor

These soil properties will be defined in this study for the 12 soil textures presented in Fig. 1. These properties will be collected from multiple studies, measurements, and standards, and empirical formulas will be created and used to estimate their variations as a function of different parameters. The influence of gravity on water movement in soil is typically neglected because the water pressure head is usually much higher than the gravitational pressure (Gopalakrishnan and Manik 2007, Prunty 2009).

\subsection{MOISTURE STORAGE FUNCTION}

The van Genuchten equation for the estimation of soil hydraulic properties has been widely used since it was first published in 1980 (Neto et al. 2011, van Genuchten 1980, Zhou and Yu 2005). In the equation, the soil water retention curve (WRC) defines the relationship between the volumetric water content of the 
soil as a function of the soil water pressure head, $h$, or suction pressure, $p_{s u c}$. The WRC can be obtained by use of the analytical expression of the effective saturation (also referred to as normalized water content), $S_{e}$ :

$$
S_{e}(h)=\frac{\theta-\theta_{\mathrm{r}}}{\theta_{\mathrm{s}}-\theta_{\mathrm{r}}}=\left[1+(\alpha|h|)^{n}\right]^{-m} .
$$

Hence, the volumetric water content can be expressed as

$$
\theta(h)=\theta_{\mathrm{r}}+\frac{\theta_{\mathrm{s}}-\theta_{\mathrm{r}}}{\left[1+(\alpha|h|)^{n}\right]^{m}}
$$

where

$S_{e}=$ effective saturation,

$\theta=$ volumetric water content $\left(\mathrm{cm}^{3} / \mathrm{cm}^{3}\right)$,

$\theta_{\mathrm{r}}=$ residual water content $\left(\mathrm{cm}^{3} / \mathrm{cm}^{3}\right)$,

$\theta_{\mathrm{s}}=$ volumetric water content at saturation $\left(\mathrm{cm}^{3} / \mathrm{cm}^{3}\right)$,

$h=$ soil water pressure head $(\mathrm{cm})$,

$\alpha$ and $n$ are fitting parameters $\left(\mathrm{cm}^{-1}\right.$ and dimensionless, respectively),

$m=(1-1 / n)$.

The parameter $n$ is related to the pore size distribution where a larger value corresponds to more uniform pore sizes (Zhou and $\mathrm{Yu}$ 2005). The value of $\alpha$ is related to the inverse of the air entry suction (Schaap, Leij, and van Genuchten 2001), and $m$ is related to the asymmetry of the curve (Zhou and Yu 2005). The soil textures analyzed in this study (the type of soils for which essential properties for hygrothermal simulation will be defined) correspond to the 12 texture classes used by the Natural Resources Conservation Service of the US Department of Agriculture (Noorallah 1999). The soil texture classes are defined in Table 1, where the input parameters are based on 560 soil samples obtained from a computer program for estimating soil hydraulic characteristics (Schaap 2002).

Table 1. Average hydraulic parameters required in Eq. (1) to calculate the saturation effect and in Eq. (13) to calculate the liquid diffusivity

The values are based on 560 soil samples (Schaap 2002).

\begin{tabular}{lcccccc}
\hline \multicolumn{1}{c}{ Soil texture } & $\begin{array}{c}\mathbf{\theta}_{\mathbf{r}} \\
\left(\mathbf{c m}^{\mathbf{3}} / \mathbf{c m}^{\mathbf{3}}\right)\end{array}$ & $\begin{array}{c}\mathbf{\theta}_{\mathbf{s}} \\
\left(\mathbf{c m}^{3} / \mathbf{c m}^{\mathbf{3}}\right)\end{array}$ & $\begin{array}{c}\boldsymbol{\alpha} \\
\left(\mathbf{c m}^{-\mathbf{1}}\right)\end{array}$ & $\begin{array}{c}\mathbf{N} \\
(-)\end{array}$ & $\begin{array}{c}\mathbf{m} \\
(-)\end{array}$ & $\begin{array}{c}\mathbf{K}_{\mathbf{s}} \\
(\mathbf{c m} / \mathbf{d a y})\end{array}$ \\
\hline Clay & 0.10 & 0.46 & 0.01 & 1.25 & 0.20 & 14.8 \\
Clay loam & 0.08 & 0.44 & 0.02 & 1.42 & 0.29 & 8.2 \\
Loam & 0.06 & 0.40 & 0.01 & 1.47 & 0.32 & 12.1 \\
Loamy sand & 0.05 & 0.39 & 0.03 & 1.75 & 0.43 & 105.2 \\
Sand & 0.05 & 0.38 & 0.04 & 3.18 & 0.69 & 642.7 \\
Sandy clay & 0.12 & 0.39 & 0.03 & 1.21 & 0.17 & 11.4 \\
Sandy clay loam & 0.06 & 0.38 & 0.02 & 1.33 & 0.25 & 13.2 \\
Sandy loam & 0.04 & 0.39 & 0.03 & 1.45 & 0.31 & 38.3 \\
Silt & 0.05 & 0.49 & 0.01 & 1.68 & 0.40 & 43.8 \\
Silty clay & 0.11 & 0.48 & 0.02 & 1.32 & 0.24 & 9.6 \\
Silty clay loam & 0.09 & 0.48 & 0.01 & 1.52 & 0.34 & 11.1 \\
Silt loam & 0.07 & 0.44 & 0.01 & 1.66 & 0.40 & 18.2 \\
\hline
\end{tabular}


The sorption isotherm describes the water content, $w\left(\mathrm{~kg} / \mathrm{m}^{3}\right)$, of a material as a function of the relative humidity, $w(\varphi)$ or $w(\mathrm{RH})$, which is an essential parameter when making hygrothermal calculations with porous materials. The WRC, thus the soil water pressure head, $p_{s u c}$, can be expressed as the relative humidity with the Kelvin-Thomson equation (Kiessl and Gertis 1980):

$$
\varphi=e^{\left[\frac{-2 \sigma}{r \cdot \rho_{w} \cdot R_{D} \cdot T}\right]}
$$

and

$$
p_{\text {suc }}=\frac{2 \cdot \sigma \cdot \cos \gamma}{r}
$$

where

$\varphi=$ relative air humidity $(\%)$,

$\sigma=$ surface tension coefficient $(\mathrm{N} / \mathrm{m})$,

$r=$ radius of capillary tube $(\mathrm{m})$,

$\rho_{w}=$ density of water $\left(\mathrm{kg} / \mathrm{m}^{3}\right)$,

$R_{D}=$ water vapor gas constant, $461.5(\mathrm{~J} / \mathrm{kg} \cdot \mathrm{K})$,

$T=$ temperature $(\mathrm{K})$,

$p_{\text {suc }}=$ suction pressure $(\mathrm{Pa})$,

$\gamma=$ contact angle $(\mathrm{deg})$.

The contact angle, $\gamma$, between the water meniscus and the capillary walls can be assumed equal to zero (Hagentoft 2001); hence the radius of the capillary tube can be expressed as

$$
r=\frac{2 \cdot \sigma}{p_{s u c}}
$$

The relative humidity in (3) can be expressed as function of $p_{s u c}$ :

$$
\varphi\left(p_{\text {suc }}\right)=e^{\left[\frac{-p_{s u c}}{\rho_{w^{\prime}} \cdot D^{\cdot T}}\right]}
$$

The soil water pressure head, $h$, can be described as suction pressure, $p_{\text {suc }}$ :

$$
h \cdot g \cdot \rho_{w}=p_{s u c} .
$$

Combining (6) and (7) results in

$$
h(\varphi)=\frac{-\ln \varphi \cdot R_{D} \cdot T}{g}
$$


Further, the volumetric water content in (2) can be expressed as a function of $\varphi$.

$$
\theta(\varphi)=\theta_{\mathrm{r}}+\frac{\theta_{\mathrm{S}}-\theta_{\mathrm{r}}}{\left[1+\left(\alpha\left(\frac{-\ln \varphi \cdot R_{D} \cdot T}{g}\right)\right)^{n}\right]^{m}}
$$

The relation between the water content, $w$, and the volumetric water content, $\theta$, is

$$
w=\rho_{w} \cdot \theta
$$

Finally, $w$ can be expressed as a function of $\varphi$ with the van Genuchten equation:

$$
w(\varphi)=\rho_{w}\left[\theta_{\mathrm{r}}+\frac{\theta_{\mathrm{s}}-\theta_{\mathrm{r}}}{\left[1+\left(\alpha\left(\frac{-\ln \varphi \cdot R_{D} \cdot T}{g}\right)\right)^{n}\right]^{m}}\right] .
$$

Obviously $\varphi$ in (6) cannot be described solely as a function of the $p_{\text {suc. }}$. Temperature also has an influence on the suction pressure, though proven almost insignificant in the temperature range between 0 and $20^{\circ} \mathrm{C}$ (Fig. 2). Therefore, in this study, the temperature is assumed to be $10^{\circ} \mathrm{C}$. The resulting moisture storage functions of the 12 soil textures, based on Eq. (11), are presented in Appendix A.

Hysteresis is defined as the difference in moisture storage capacity of a material depending on the state from which the material is moving from. A material that is in a drying process has a higher moisture storage capacity at a given $\varphi$ than a material that is in a wetting process (Hagentoft 2001). The effect of hysteresis on hydraulic soil properties has been investigated (Simůnek et al. 1999) but will not be taken into account for the moisture storage capacity, though considered in the liquid diffusivity, defined in Section 2.2.

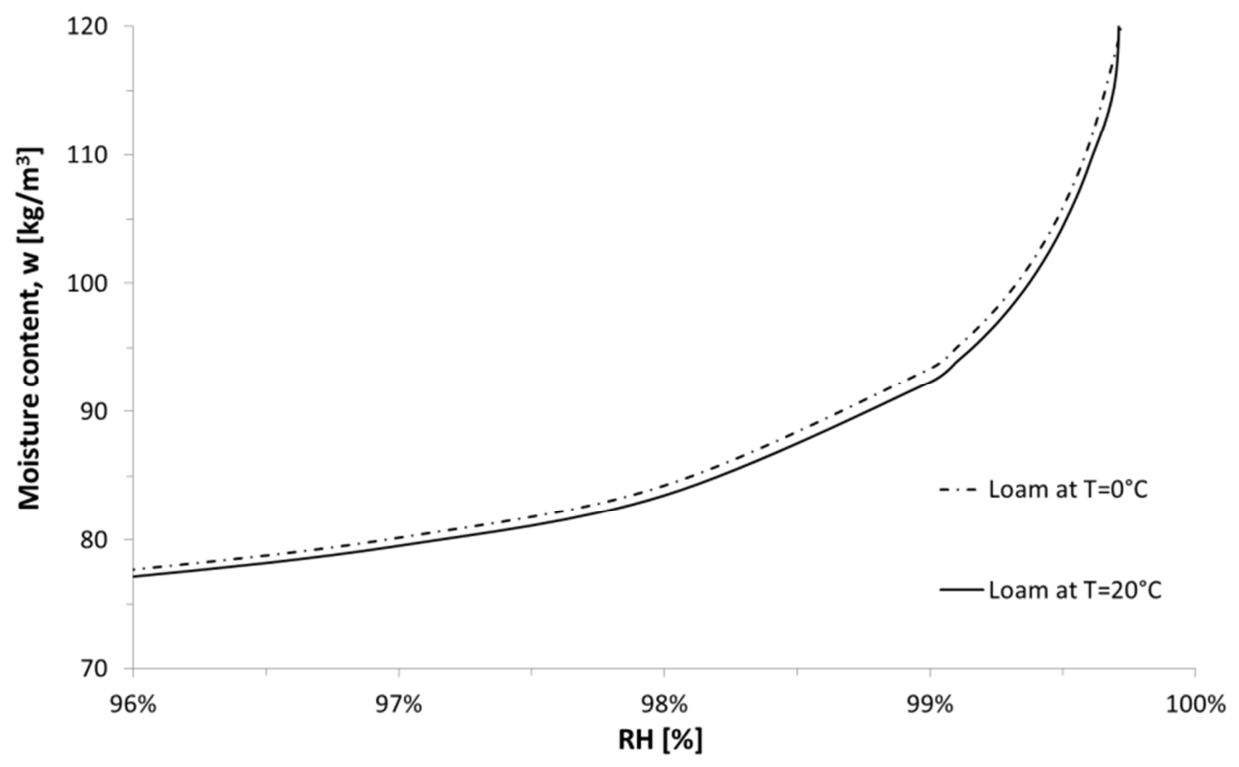

Fig. 2. Moisture storage function of loam at fixed temperatures of 0 and $20^{\circ} \mathrm{C}$. The moisture content of the soil is defined in the range $96-100 \%$ RH. 


\subsection{LIQUID DIFFUSIVITY}

The liquid transport coefficient, also referred to as liquid diffusivity, $D$, can be expressed with Darcy's equation for one-dimensional water flux as a function of the WRC (Gopalakrishnan and Manik 2007, Hills et al. 1989, Prunty 2009):

$$
D(\theta)=K(\theta) \frac{\partial h}{\partial \theta}
$$

in which $K$ is hydraulic conductivity as a function of volumetric water content. Further, liquid diffusivity can be expressed as a function of the effective saturation, $S_{e}$, for unsaturated soils (van Genuchten 1980):

$$
D\left(S_{e}\right)=\frac{(1-m) K_{s}}{\alpha m\left(\theta_{s}-\theta_{r}\right)} S_{e}^{\left(\frac{1}{2}-\frac{1}{m}\right)}\left[\left(1-S_{\left.e^{\frac{1}{m}}\right)^{-m}}+\left(1-S_{\left.\left.e^{\frac{1}{m}}\right)^{m}-2\right]}\right.\right.\right.
$$

where

$D=$ liquid diffusivity $\left(\mathrm{cm}^{2} /\right.$ day $)$,

$K_{s}=$ saturated hydraulic conductivity (cm/day),

and all other variables are specified in (2).

In addition, the value of liquid diffusivity varies according to whether the soil is being dried or wetted i.e. an effect of hysteresis. The liquid diffusivity for a soil that is being dried is referred to as drying or drainage diffusivity, whereas a soil being wetted is referred to as wetting or absorption diffusivity. In this study, the terms drying diffusivity, $D_{d r y}$, and wetting diffusivity, $D_{\text {wet }}$, are applied.

Eq. (13) represents the drying liquid diffusivity (Mabirizi 2000); hence

$$
D\left(S_{e}\right)=D_{d r y}\left(S_{e}\right)
$$

Consequently, the wetting diffusivity also needs to be established. There exist very few measurements of both drying and wetting diffusivities where the latter can be determined either by Mitchell's Test Method (Mabirizi and Bulut 2009) or by the relation between the drying and wetting diffusivities in which either of the unknown diffusivities can be estimated. In this study, a relation factor, $\beta$, is applied:

$$
D_{\text {wet }}=\frac{D_{d r y}}{\beta}
$$

The effects of the disparity between the wetting and drying soil conditions and of the moisture storage function in (11) have been investigated, using the input parameters of van Genuchten (Šimůnek et al. 1999). According to the authors, the hysteresis can be taken into account for WRC of unsaturated soils by making the following assumption of the fitting parameter $\alpha$ :

$$
\alpha_{w e t}=2 \cdot \alpha_{d r y}=\frac{\alpha_{d r y}}{\beta} .
$$


This assumption is proven to work well for the moisture storage function in (2) (Šimůnek et al. 1999); According to a study of 40 different samples comprising six different soil types, the relation factor, $\beta$, may vary between 0.6 and 3.9 (Mabirizi and Bulut 2009), where the overall average of $\beta$ from the measurements is 1.75 .

In this study, $D_{d r y}$ is determined with (13) together with the input parameters defined for the 12 soil textures in Table 1. $D_{\text {wet }}$ is determined with the relation factor of 1.75 in (15). $D_{d r y}$ values for the defined soil texture classes are presented in Appendix B together with $D_{\text {wet }}$ for clay and silt. The necessity of distinguishing the liquid diffusivity into $D_{d r y}$ and $D_{\text {wet }}$ might be question due the small disparity of their distributions. Still, the two different diffusivities remain in this study.

The diffusivities are presented with the moisture content, $w$, which can be expressed as a function of effective saturation (combining (1) and (10)):

$$
w\left(S_{e}\right)=\left(S_{e}\left(\theta_{\mathrm{s}}-\theta_{\mathrm{r}}\right)+\theta_{\mathrm{r}}\right) \rho_{w}
$$

\subsection{VAPOR DIFFUSION RESISTANCE FACTOR}

The water vapor diffusion resistance factor, $\mu$, that is, the rate of vapor diffusion through a material in comparison with stagnant air, is typically assumed to be 50 for soils (EN 12524, 2000), which corresponds to a permeability of about 2.6 perm-inch.

\subsection{DRY BULK DENSITY, PARTICLE DENSITY, AND POROSITY}

The bulk density of soil is the combined weight of the soil solids, water, and air divided by the bulk volume $\left(\mathrm{kg} / \mathrm{m}^{3}\right)$. The dry bulk density, $\rho_{b}$, which is an important material property, is the bulk density for a completely dry soil. The bulk density typically increases with soil depth on account of reduced organic materials and natural compaction (USDA 2008). Compaction is the phenomenon by which soils are compressed, which usually decreases the porosity (Richard et al. 2001) and thus the ability for water and vapor absorption. Other research has shown that the bulk density varies mainly down to $30 \mathrm{~cm}$ (Kim et al. 2010) where a 7\% increase in bulk density can be expected from 0 to $1 \mathrm{~m}$ (Ray, Vogel, and Dusek 2004). In this study, the effect of compaction will not be taken into account when estimating soil material properties.

In addition, the bulk density depends on the soil type (Keller and Håkansson 2010). Table 2 presents the variation in $\rho_{b}$ for the 12 specified soil textures, based on the average values of 560 soil samples (Schaap 2002).

Table 2. Dry bulk density, particle density, and porosity for the 12 soil textures where the bulk and particle density are obtained from averages of 560 soil samples (Keller and Håkansson 2010, Schaap 2002)

\begin{tabular}{lccc}
\hline \multicolumn{1}{c}{ Soil texture } & $\begin{array}{c}\text { Dry bulk density, } \boldsymbol{\rho}_{\boldsymbol{b}} \\
\left(\mathbf{k g} / \mathbf{m}^{\mathbf{3}}\right)\end{array}$ & $\begin{array}{c}\text { Particle density, } \boldsymbol{\rho}_{\boldsymbol{s}} \\
\left(\mathbf{k g} / \mathbf{m}^{\mathbf{3}}\right)\end{array}$ & $\begin{array}{c}\text { Porosity, } \boldsymbol{n} \\
(\boldsymbol{\%})\end{array}$ \\
\hline Clay & 1.27 & 2.62 & 52 \\
Clay loam & 1.36 & 2.60 & 48 \\
Loam & 1.29 & 2.60 & 50 \\
Loamy sand & 1.51 & 2.64 & 43 \\
Sand & 1.58 & 2.65 & 40 \\
Sandy clay & 1.40 & 2.65 & 47 \\
\hline
\end{tabular}




\begin{tabular}{lccc}
\hline Sandy clay loam & 1.52 & 2.62 & 42 \\
Sandy loam & 1.55 & 2.58 & 40 \\
Silt & 1.39 & 2.65 & $48(49)^{a}$ \\
Silty clay & 1.40 & 2.61 & $47(48)^{a}$ \\
Silty clay loam & 1.28 & 2.59 & 50 \\
Silt loam & 1.44 & 2.60 & 45 \\
\hline
\end{tabular}

${ }^{a}$ The two values in parentheses are adjusted values used in this study because the volumetric water content at saturation, $\theta_{\mathrm{s}}$, cannot exceed the porosity [see Eq. (19)].

The particle density, $\rho_{s}$, in soils is defined as the mass of the solids divided by the volume of the solids. Consequently, without considering the volume of the pores or the mass of liquid and gas inside the pores, the particle density can be used to determine the porosity, $n$, in relation with the bulk density:

$$
n=\left(1-\frac{\rho_{b}}{\rho_{s}}\right) \geq \theta_{\mathrm{s}}
$$

Naturally, the volumetric water content at saturation, $\theta_{\mathrm{s}}$, cannot exceed the porosity, if the swelling phenomenon is neglected.

The particle density of soils and earth materials is typically assumed to be $2.65 \mathrm{~kg} / \mathrm{dm}^{3}$ (Blanco-Canqui et al. 2006, Eshel et al. 2004) though variation exists between 2.4 and $2.9 \mathrm{~kg} / \mathrm{dm}^{3}$ depending on the composition of minerals and organic components (Rühlmann, Körschens, and Graefe 2006). An existing study presents the particle densities from 176 experimental sites (Keller and Håkansson 2010), which include nine of the 12 defined soil textures. In this study, these variations are applied. The particle density of the other three soil textures, which is not included, is assumed to equal $2.65 \mathrm{~kg} / \mathrm{dm}^{3}$. The particle densities and porosities for the 12 soil textures are presented in Table 2.

\subsection{THERMAL CONDUCTIVITY AND HEAT CAPACITY}

The thermal conductivity, $k$, of soils increases with the moisture content (Abu-Hamdeh 2003). Other factors that influence the conductivity, though slightly, are mineral composition, temperature, soil texture, and time (Becker and Fricke 1997). An empirical solution of $k$ has been defined on the basis of the available data collected from the literature as a function of effective saturation, $S_{e}$, of three different soil textures: sand, silt, and clay (Becker and Fricke 1997):

$$
S_{e}(k)=\lambda_{1}\left[\sinh \left(\lambda_{2} \cdot k+\lambda_{3}\right)-\sinh \left(\lambda_{4}\right)\right] .
$$

Hence, $k$ can be defined as

$$
k\left(S_{e}\right)=\frac{-\left(\lambda_{3}-a \sinh \left(\sinh \left(\lambda_{4}\right)+\frac{S_{e}}{\lambda_{1}}\right)\right)}{\lambda_{2}}
$$

where

$S_{e}=$ effective saturation, (-)

$k=$ soil thermal conductivity $(\mathrm{W} / \mathrm{m}, \mathrm{K})$, 
$\lambda_{1-4}=$ coefficients varying with soil type.

Table 3 displays the coefficients required for determining the thermal conductivity of sand, clay, and silt. In addition, there are different values of these coefficients depending on whether the soils are frozen or unfrozen.

Table 3. Coefficients for clay, sand, and silt (frozen and unfrozen) required to estimate the soil thermal conductivity by Eq. (21) (Becker and Fricke 1997)

\begin{tabular}{clcccc}
\hline \multicolumn{2}{c}{ Soil Type } & $\boldsymbol{\lambda}_{\mathbf{1}}$ & $\boldsymbol{\lambda}_{\mathbf{2}}$ & $\boldsymbol{\lambda}_{\mathbf{3}}$ & $\boldsymbol{\lambda}_{\mathbf{4}}$ \\
\hline \multirow{2}{*}{ Clay } & Frozen & 14.5 & 1.7 & -2.5 & -2.0 \\
& Unfrozen & 27.0 & 1.8 & -1.5 & -1.0 \\
\multirow{3}{*}{ Sand } & Frozen & 10.0 & 1.7 & -2.2 & -1.6 \\
& Unfrozen & 6.8 & 2.8 & -2.9 & -1.5 \\
\multirow{2}{*}{ Silt } & Frozen & 19.5 & 1.9 & -1.8 & -1.5 \\
& Unfrozen & 17.0 & 2.8 & -2.6 & -1.6 \\
\hline
\end{tabular}

The results of calculating the soil thermal conductivity by (20) for clay, sand, and silt are presented in Appendix $\mathrm{C}$, though as a function of water content, $w$. The water content is expressed as a function of effective saturation in (17); hence $k(w)$ becomes

$$
k(w)=\frac{-\left(\lambda_{3}-\operatorname{asinh}\left(\sinh \left(\lambda_{4}\right)+\frac{\left(w \cdot \rho_{W}^{-1}-\theta_{\mathrm{r}}\right)}{\left(\theta_{\mathrm{S}}-\theta_{\mathrm{r}} \lambda_{1}\right.}\right)\right)}{\lambda_{2}} .
$$

The soil thermal conductivities for clay, sand, and silt, both frozen and unfrozen, are presented in Appendix $\mathrm{C}$ in relation to soil water content.

Of the 12 soil textures defined by the USCA, sand, silt, and clay are the three major ones, with the other nine textures defined from them. No coefficients are presented for these nine textures (Becker and Fricke 1997) since, in this study, an interpolation have been made based on the distributions of the thermal conductivity of clay, sand, and silt. The interpolation is also based on the assumption that these three major textures are not pure clay, sand, and silt; instead, they are assumed to have their average composition given by Fig. 1. The reason behind this approach is that the coefficients for the thermal conductivity presented in Table 3 are based on multiple samples within the range of clay, sand, or silt. Thus the coefficients of clay, sand, and silt represent average values. The assumed compositions of the three provided soil textures are presented in Table 4 . The soil compositions are the basis for obtaining the thermal conductivities for intermediate soil textures with a system of linear equations. This method, together with results, is presented in Appendix D.

Table 4. Assumed texture compositions of clay, sand, and silt

These compositions are the basis for estimating the unknown conductivities for the nine soil textures that are not defined in Table 3.

\begin{tabular}{lccc}
\hline \multicolumn{1}{c}{$\begin{array}{c}\text { Average } \\
\text { composition }\end{array}$} & \multicolumn{3}{c}{ Portion of (\%) } \\
\cline { 2 - 4 } Clay & Clay & Sand & Silt \\
Sand & 60 & 20 & 20 \\
Silt & 5 & 90 & 5 \\
\hline
\end{tabular}


The resulting soil thermal conductivities for sand, loam, silt, and silty clay are presented in Fig. 3. The distributions of loam and silty clay rely on their defined portion of clay, sand, and silt, which then are implemented into the result of a system of linear equations described in Appendix D.

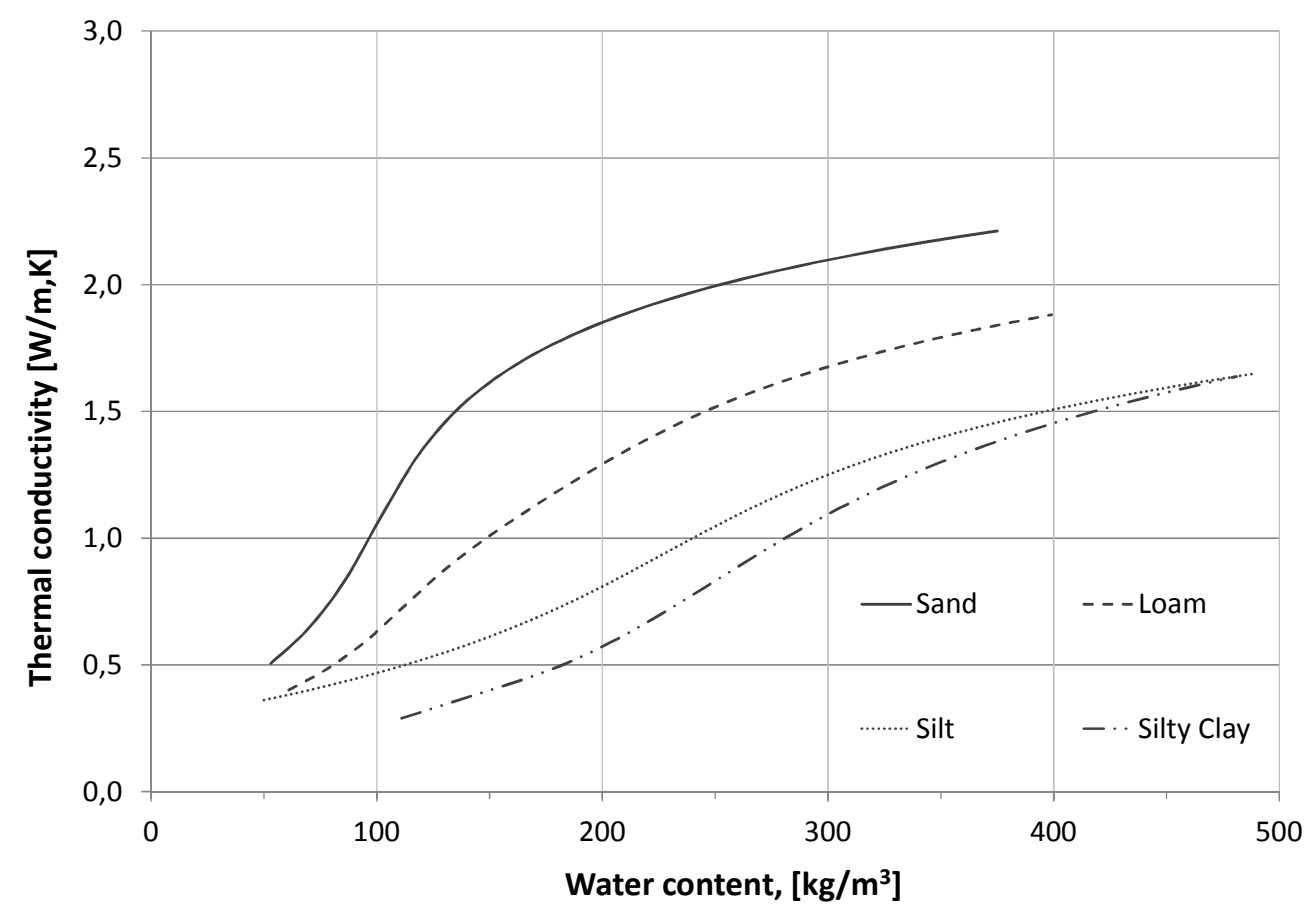

Fig. 3. Thermal conductivity for sand, loam, silt, and silty clay as a function of the water content of the soils. The distributions of loam and silty clay are based on determining their compositions and on the provided distributions of clay, sand, and silt (see Appendix D).

The specific heat capacity of dry soils, $c_{d r y}$, can vary from 710 to $1550 \mathrm{~J} / \mathrm{kgK}$ (Olchev et al. 2009), though most commonly $c_{d r y}$ is assumed to be about $850 \mathrm{~J} / \mathrm{kg}, \mathrm{K}$ (Acs, Mihailovic, and Rajkovic 1990; Kung and Steenhuis 1986), where the actual volumetric heat capacity of the soil, $c$, increases linearly with the soil moisture content:

$$
c=\rho_{b} \cdot c_{d r y}+w \cdot c_{w}
$$

where $\rho_{b}$ is the dry bulk density $\left(\mathrm{kg} / \mathrm{m}^{3}\right), w$ is the water content, and $c_{w}$ is the specific heat capacity of water $(\mathrm{J} / \mathrm{kg}, \mathrm{K})$.

\section{VALIDATION WITH THERMAL SOIL MEASUREMENT}

Since 1987 the temperatures at different depths of a local soil have been measured at Fraunhofer Institute for Building Physics in Holzkirchen, Germany. Three different temperatures are measured hourly: at the surface and at the depths of 0.5 and $1.0 \mathrm{~m}$. Simultaneously, at the same location, comprehensive weather data have been measured, which enables the thermal behavior of the soil to be validated by a computer simulation. The typical soil in the Holzkirchen area is loamy sand (LFU Bayern 2012), the properties of which are applied in the simulation model discussed in Chapter 2. 
In this study, the period from 2005 to 2009 has been simulated in WUFI 1D (Künzel 1995) for the comparison and thermal validation of the soil properties. The model has been designed to represent the semi-infinite conditions of one-dimensional heat transfer through the ground according to Fig. 4.

\section{Outdoor climate of Holzkirchen}

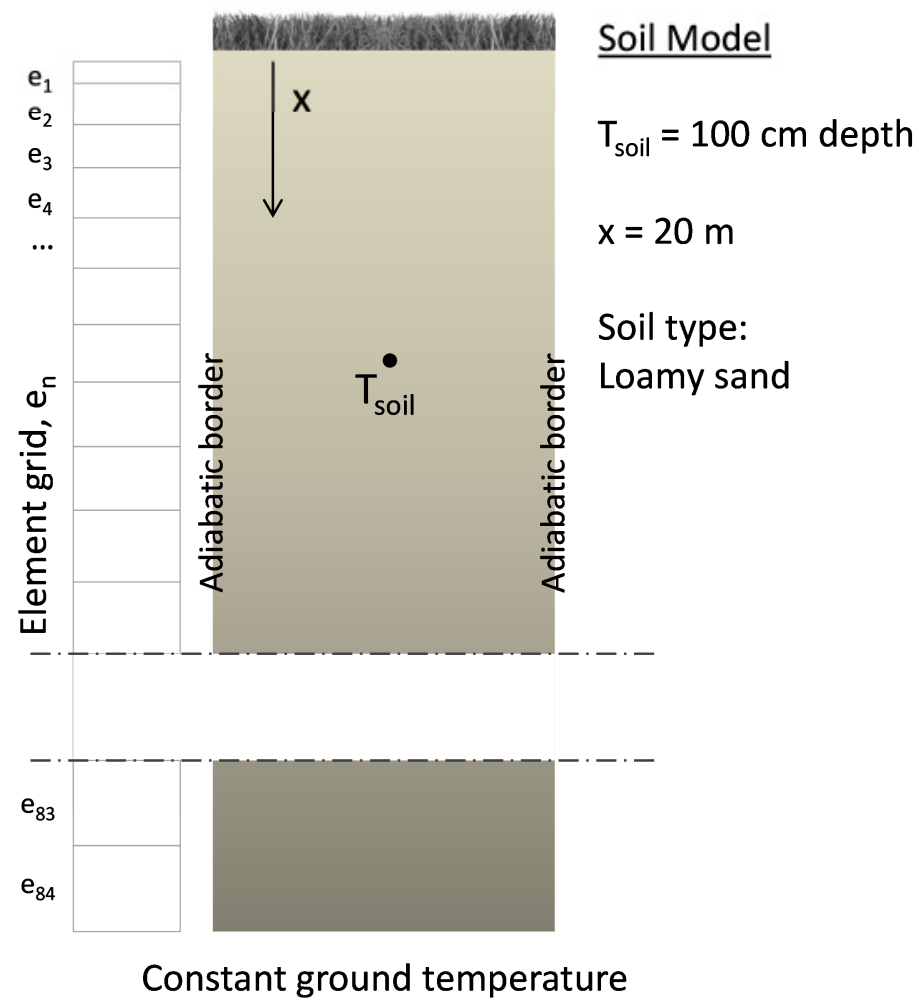

Fig. 4. Simulation model representing one-dimensional and semi-infinite hygrothermal transfer through the ground. The soil material in the simulation model is loamy sand from which the temperature variation at the depth of $1 \mathrm{~m}$ is compared with measurements. The temperature is assumed constant at a depth of $20 \mathrm{~m}$, and the border moisture is assumed to be adiabatic.

Typically, the precipitation in a simulation model functions as a boundary condition in which the moisture load initially affects only the grid element closest to the border, $\mathrm{e}_{1}$. If this element is saturated, it will not have further moisture buffering capacity; hence, the surplus of moisture is neglected. This assumption is acceptable for a surface with drainage (e.g., a vertical wall) though not applicable in soils in which most of the precipitation will be absorbed eventually. Instead, in this model, the precipitation is distributed directly into the first four elements, $e_{1}$ to $e_{4}$, as an impregnated source (see Fig. 4). This approach decreases the amount of precipitation neglected during the simulation run and serves as the best practice manageable with the current WUFI model.

The temperature variations of the ground vary with the surface temperature, with the amplitude of the average temperature decreasing with ground depth. At the depth of $10 \mathrm{~m}$, the annual temperature variation of a typical soil is about $4 \%$ of the temperature variation at the surface (Hagentoft 2001). At the depth of $20 \mathrm{~m}$, the corresponding variation is $0.2 \%$, which is the depth used in the simulation model of this study. The average ground temperature at Holzkirchen is estimated to $9.5^{\circ} \mathrm{C}$ (Heidreich 2006), which is the 
assumed constant temperature at the ground boundary (i.e., at the depth of $20 \mathrm{~m}$ ). This approach simplifies the semi-infinite temperature variations of the ground for a model defined by boundaries.

The moisture transfer of the ground behaves accordingly. In this study, the starting moisture content of the soil is based on 10 years of pre-simulation where the moisture content of the lower boundary remains constant. This assumption does not enable moisture to pass the lower boundary; hence the moisture content of the simulation model, at different depths, varies solely on the basis of the variation of the moisture content at the upper surface of the ground. Future enhancements to the WUFI software will attend to this deficiency.

The results of the comparison between simulated and measured ground temperature in soil at Holzkirchen are presented in Fig. 5. The slightly lower simulated ground temperature between July and October could be a result of a too high surface heat transfer coefficient. In the simulation model, the wind-driven heat transfer coefficient is assumed to represent the clean horizontal surface of a flat roof, though in reality there are other factors that should be taken into account. First, the surface of the ground is not clean and smooth. The texture of the grass will affect the surface wind velocity, thus the convection-induced heat transfer. Further, the measurement of the ground temperature is taken in the vicinity of other objects, such as buildings, which naturally also will have an effect. A brief analysis of the effects of these factors on the heat transfer coefficient was performed, revealing a better fit between the measured and the simulated temperature variations.

Additionally, neither snow coverage nor its effect on the surface thermal resistance and long- and shortwave radiation is taken into account in the simulation.

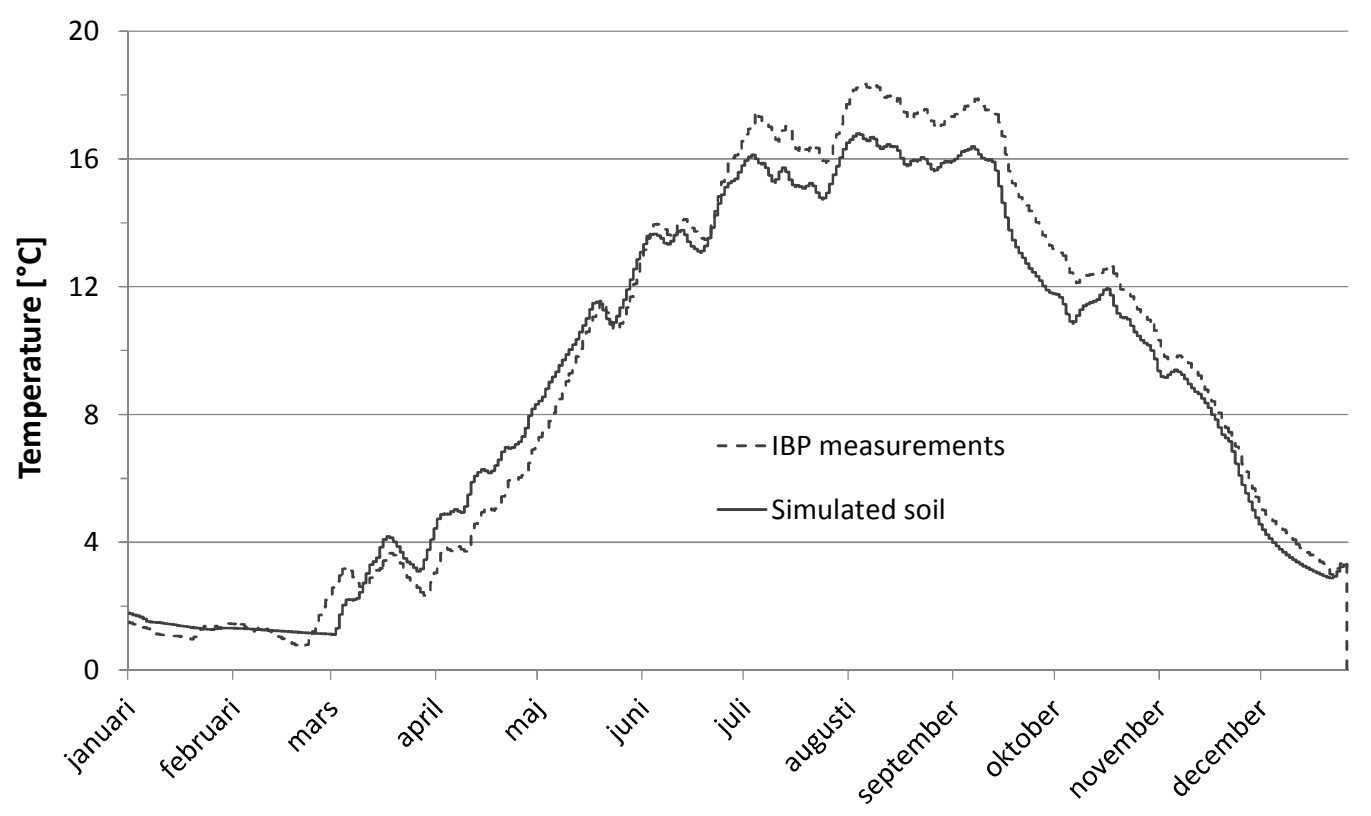

Fig. 5. Comparison between measured and simulated ground temperature at the depth of $\mathbf{1} \mathbf{~ m}$ in Holzkirchen, Germany. The presented variations in temperature occurred during the year 2008, and the soil texture was loamy sand. 


\section{FULL BASEMENT WALL HYGROTHERMAL VALIDATION DATA GENERATION EXPERIMENT ${ }^{1}$}

\subsection{EXPERIMENTAL CONFIGURATION}

Experimental basement wall systems are under construction at the University of Minnesota's Cloquet Residential Research Facility (CRRF) in Cloquet, Minnesota, which is located in climate Zone 7. A schematic drawing of the wall systems is given in Fig. 6 (the figures in this section are displayed as a collection following the text). The design of the wall system, intended for a retrofit application, was determined by the requirements of a National Renewable Energy Laboratory funded project that is part of the overall research project ${ }^{2}$ (Goldberg and Steigauf 2011). Hygrothermal and energy data will be collected from the wall systems for a minimum of 12 months. The data will be used to evaluate the accuracy of an adapted version of the WUFI hygrothermal simulation in a below-grade application discussed in previous sections of this report.

The experiment consists of two 10-ft-wide bays, each with a north and south wall of identical construction. The first bay has a silt/clay soil backfill and the second bay has a sandy soil backfill, while all the other construction elements of the two bays are identical. An enclosure measuring $3 \mathrm{ft} \times 9 \mathrm{ft} \times$ $7 \mathrm{ft} 7 \mathrm{in}$. deep that fits tight to the basement wall and extends down to the top of the building footing is used to contain the imported soils. The enclosure is a PVC frame wrapped with Platon ${ }^{\circledR}$ waterproofing membrane on three sides (top and bottom are open) to separate the imported soil from the adjacent native soils and create a watertight perimeter (Figs. 7 and 9). A water spray system will be installed at the beginning of spring 2013 at the top of the soil containment enclosures, enabling measured quantities of water to be delivered to the contained soils to achieve a controlled soil moisture content profile in the absence of precipitation. This system will be utilized only during the cooling season (approximately May through September).

The basement walls are constructed of 12 in. concrete blocks that are assumed to have a "stretcher" configuration. The blocks are covered on their exterior surface with a masonry parging painted with a bituminous damp-proofing. On the inside face of the basement wall, CCW Miradri 860/861 waterproofing membrane [forming the 2012 MN Energy Code required Water Separation Plane (WSP)] was adhered to the concrete block wall with CCW 702 quick-dry sheet membrane adhesive. Three inches of Styrofoam $^{\mathrm{TM}}$ extruded polystyrene insulation (per 2012 International Energy Conservation Code) was fitted tight to the waterproofing membrane, and the top, bottom, and vertical joints were sealed with PL® 300 foam board construction adhesive. A $2 \times 3$ stud frame with studs at 24 in. o.c. was constructed against the insulation; $1 / 2$ in. gypsum board will be attached to the stud frame.

The basement interior temperature and humidity will be controlled during the heating season by an electric furnace and a steam humidifier, respectively. During the cooling season, dehumidification will be performed by a standalone dehumidifier; temperature will not be controlled as there is no air conditioning system in the building.

\footnotetext{
${ }^{1}$ This section was contributed by Anna Harmon, PE, M.S. Graduate Student, and Louise F. Goldberg, PhD (Eng), Principal Investigator, of the Energy Systems Design Program, Department of Bioproducts and Biosystems Engineering, University of Minnesota.

${ }^{2}$ The overall project is being co-funded by the Oak Ridge National Laboratory and the National Renewable Energy Laboratory (as part of the University of Minnesota's NorthernSTAR Building America program).
} 


\subsection{INSTRUMENTATION}

The instrumentation used in the project is listed in Table 5 and has been acquired specifically for the project. Note that the instrumentation in the existing CRRF weather station is not listed, as the details of this instrumentation would have to be gleaned from the instruments themselves, most of which are located on a mast and thus are not readily accessible.

Table 5. Purchased instrumentation

\begin{tabular}{lll}
\hline \multicolumn{1}{c}{ Instrument } & \multicolumn{1}{c}{ Manufacturer } & \multicolumn{1}{c}{ Model No. } \\
\hline Pyrgeometer FIR (4500-42000 nm) & Kipp and Zonen & CGR3 \\
Ultrasonic snow depth gauge & Campbell Scientific & SR50A-1 \\
Heated precipitation gauge & RM Young & 52202 \\
Relative humidity & Honeywell & HIH-4000-003 \\
Thermocouple & Omega Engineering & PR-T-24-SLE \\
Heat flux plate & Concept Engineering & F-002-4 HFP \\
Soil moisture content and temperature & Stevens Water Monitoring Systems, Inc. & Hydraprobe \\
\hline
\end{tabular}

The following data will be collected on each test bay wall:

- $\quad$ soil moisture content

- soil temperature

- moisture content of the concrete block

- temperature

- absolute humidity

- heat flux

Figure 6 shows the instrumentation layout. All instruments were located using the top of the wall as a reference point.

On the interior face of the block wall, the temperature sensors were located at the horizontal midpoint of the concrete block core nearest the centerline of the $10 \mathrm{ft}$ bay (Fig. 10). The concrete blocks that comprise the wall are not perfectly aligned; therefore, the temperature sensors are not perfectly aligned vertically. At the exterior face of the wall, the existing damp-proofing covered the concrete block from the top of the footing to $8 \mathrm{in}$. below of the top of the wall. The top exterior block wall temperature sensor was located with the same method used at the interior. The remainder of exterior block wall temperature sensors were aligned with the top exterior block wall temperature sensor; therefore, they were not precisely aligned with the midpoint of the concrete block core because the parging/damp-proofing rendered the exterior surface of the masonry blocks invisible (Figs. 7 and 8). On the interior of the wall system, the horizontal difference between the locations of the temperature sensors on the interior face of the block wall was averaged and the temperature sensors located on the face of insulation, on the back of the gypsum board and in the room, were located along this line (Fig. 13).

The soil moisture content and soil temperature sensors have three long prongs that were positioned vertically in the soil. The midpoint of the prongs was aligned with the elevation of the exterior concrete block wall temperature sensors. As the prongs are about $3 \mathrm{in.} \mathrm{long,} \mathrm{this} \mathrm{provides} \mathrm{for} \mathrm{at} \mathrm{least} 1.5 \mathrm{in}$. of settlement before the sensor becomes vertically misaligned. 
The concrete block moisture sensors were placed in the same concrete block as the temperature sensor at the corresponding elevation. A concrete block moisture sensor consists of two probes spaced horizontally approximately $101 / 16 \mathrm{in}$. apart. The midpoint between the probes corresponds with the midpoint of the concrete block, and the probes were located at the block mid-height. Since the concrete block moisture sensors were always placed at mid-height of the concrete block, there is an offset between the block moisture sensor and the corresponding temperature sensor (Fig. 10). On the exterior face, the moisture sensors were located the same distance from the top of wall as they were on the interior; again, this was done because the damp-proofing system prevented visual confirmation that the sensors were at the midheight of the block (Figs. 7 and 8).

Generally, the absolute humidity sensors in the block wall cores were located in the same concrete block as the temperature sensor, but in the adjacent core. A hole was drilled in the interior face of the concrete block wall $1 \frac{1}{2} \mathrm{in}$. above the midpoint of the block, and the humidity sensor was installed at a 15 -degree downward angle from the horizontal and positioned vertically so that the sensor port is at the concrete block mid-height (Fig. 10). The sensors were installed at an angle to prevent moisture accumulation within the sensor. Horizontally, the sensor is centered in the core of the concrete block. The top humidity sensor was moved down one course and the bottom humidity sensor was moved up one course from the locations of the corresponding temperature sensors because the top and bottom masonry block courses are filled with grout.

The absolute humidity sensors on the interior face of the WSP were installed by cutting a pocket into the back of the insulation and fitting the sensor in the pocket (Fig. 12). The edge of the sensor was flush with the back face of the insulation with an open port facing the WSP. This allowed the insulation to fit tight to the wall, otherwise there would be air gaps around the humidity sensors. The sensors were offset 1 in. horizontally from the centerline of the temperature sensors located on the face of the insulation. This was done so the temperature sensors and heat flux plates have a full 3 in. of insulation and not a reduced thickness due to the pocket for the humidity sensor. The humidity sensors on the interior face of the insulation were aligned with the humidity sensors on the face of the WSP and were mounted on the face of the insulation.

The heat flux plates are located on the interior face of the WSP (Fig. 11). The plates were not embedded in the insulation, which produces a small air gap (approximately 1/8 in.) around the plate because the insulation is not flush with the waterproofing material at the heat flux plate location. The plates are 3 in. $\times 3$ in. square and were offset $1 \frac{1}{2}$ in. horizontally from the centerline of the temperature sensors located on the face of the masonry block on the side opposite the humidity sensors. This was done because the temperature sensor behind the waterproofing membrane created a small bump that would have prevented the plate from fitting tight to the membrane, and as noted above, it permits the heat flux plates to be covered by a full 3 in. of insulation. However, at one location in bay 1-south at approximately 40 in. above the floor, the bump in the WSP produced by the temperature sensor behind the waterproofing material was small enough to permit the heat flux plate to be mounted flush against the WSP. Thus at this location, the heat flux plate was not offset from the centerline of the temperature sensor and the humidity sensor was still only offset $1 \mathrm{in}$. as noted above. This means that at this location, the humidity sensor is located on top of the plate and there is a reduced insulation thickness (approximately $2.5 \mathrm{in}$.). This arrangement of sensors will be used as a comparative control to determine the relative quantitative impact of an in-line sensor arrangement compared with the standard staggered arrangement.

\subsection{AMBIENT BOUNDARY CONDITIONS}

The following ambient condition/weather data will be collected on a continuous basis at the CRRF weather station: 
- relative humidity

- temperature

- barometric pressure

- wind direction

- $\quad$ wind speed

- solar radiation (pyranometer)

- long-wave radiation in far infrared range (pyrgeometer)

The following additional ambient data will be collected at the CRRF building itself:

- snow depth adjacent to the north and south faces (ultrasonic snow depth gauge)

- precipitation (heated precipitation gauge)

\subsection{MOISTURE CONTENT OF THE CONCRETE BLOCK WALL}

One objective of the research is to collect data on the moisture content of the masonry block wall. This is likely the first time that the measurement of this parameter has been attempted on a significant scale (i.e., multiple locations simultaneously, even on the same block) and a continuous sampling basis in the public domain. ${ }^{3}$ In the context of the objective of developing hygrothermal simulation code validation grade data, foundation wall moisture contents are essential in order to overcome the limitations of relative humidity (RH) measurements under condensing conditions on the face shells and in the cores of masonry blocks. Owing to the very steep sorption isotherms at relative humidities in excess of $90 \%$ in masonry materials, very small changes in RH correspond with large changes in moisture content. The relative humidity sensors used in this experiment (individually calibrated Honeywell HIH-4000-003 thin-film capacitance) have a rated accuracy of $\pm 3.5 \%$, which is too large to adequately track the masonry moisture content in the crucial vapor condensing range. Indeed, extensive experience with these sensors has demonstrated that they tend to read $100 \% \mathrm{RH}$ at actual RHs above $95 \%$. Thus an existing low-cost impedance-based method for measuring masonry moisture contents with high precision developed by the Principal Investigator has been adopted and refined for application in this project. The advantage of the methodology is its low cost in comparison with other reported techniques such as electrical time domain reflectometry (ETDR) (Khoshbakht and Lin 2006), heated "pad" temperature time constant (Davies and Ye 2009) and low temperature co-fired ceramic resonator sensor for measuring the dielectric constant of the masonry (Maksimovic, Stojanvic, et al. 2012).

The sensors collecting the masonry block moisture content data consist of two probes spaced approximately 10-1/16 in. apart. The probes are constructed by drilling two 1/4-in.-diameter by 1 -in.-deep holes in the face shell of the block and installing an equivalently sized graphite rod, with the perimeter of the rod coated in an electrically conducting epoxy paste with graphite particles providing the conductance. A \#2 stainless steel screw (0.089 in. diameter) is then inserted into the graphite rod, and wire leads are connected to the screw. Last, the top of the screw and graphite rod are covered with epoxy to isolate the probe from surface moisture, further reducing the potential for corrosion and minimizing the intrusion of water around the perimeter of the rod and screw. The screws are installed in the graphite rod and not directly into the concrete to minimize the galvanic potential between the screw and water in the block. The electrical conducting paste fills any voids around the rod that would otherwise have the potential to fill with water and cause irregular readings.

The wire leads will be attached to a continuous $24 \mathrm{~V}$ DC power source that supplies a constant voltage across the probes. The voltage across the probes and the current flowing through them (of the order of $1 \mu \mathrm{A}$ to $1 \mathrm{~mA}$ ) will be measured and converted to a steady-state resistance. As the masonry block

\footnotetext{
${ }^{3}$ No references through 2012 were revealed by a search of the Compendex engineering database.
} 
functions as parallel resistance /capacitance, the constant applied voltage eliminates the transients produced by capacitor charging and discharging, thus allowing the steady-state resistance to be measured. To achieve the necessary precision, the voltage and current are measured with a 24-bit analog-to-digital converter. The resistance reading correlates to the block moisture content; low resistance correlates to high moisture content and vice versa. The correlation is determined in the laboratory on a test masonry block by taking resistance readings for a known set of moisture contents. The moisture content is determined on the basis of periodic mass measurements of the concrete block as it dries between the water saturated and the oven-dry states.

It needs to be noted that normal weight masonry blocks in compliance with ASTM C 90 exhibit a wide range of porosities, usually far less than the maximum specified in the standard (about $20.9 \%$ ). Specimen blocks obtained for experimental evaluation yielded porosities less than $4 \%$, while test reports of other samples found on the internet reported values of 6.8 to $7.9 \%$. The amount of water uptake in a masonry block is dependent on its porosity; thus, matching the calibration sample to the installed blocks as closely as possible is essential. This will be achieved by cutting a coupon sample out of the shell of a masonry block at the CRRF and matching it to samples that will be obtained from the supplier of the masonry blocks used in the CRRF. If a close exact match cannot be obtained, then an experimental compensation factor will be used to correct for the difference. This will be measured by comparing the resistance of the CRRF coupon sample to the sample masonry block using the same probe separation distance as a function of moisture content.

It should be noted that the wide variation of masonry block porosities encountered and their substantial deviation from the ASTM standard poses a particular challenge for hygrothermal analysis. Thus use of "standard" masonry block material properties may be invalid in any particular case (such as the CRRF).

The above installation and methodology was selected on the basis of results of laboratory tests conducted prior to placement of the sensors in the experimental walls. To determine the best procedure, six different installations were installed on a single concrete block that included the use or absence of electrical paste on the graphite rods, epoxy, or no sealing of the top of the graphite rod. A bare stainless steel screw was used as a control. The six installations were:

- graphite rod, epoxy, and paste (paste on perimeter of rods and bottom of one rod)

- graphite rod, epoxy, and paste (paste on perimeter and bottoms of rods)

- graphite rod, no epoxy, and paste (paste on perimeter and bottoms of rods)

- graphite rod, epoxy, and no paste

- graphite rod, no epoxy, and no paste

- stainless steel screw (no graphite rod, no epoxy, and no paste)

The blocks with installed sensors were submerged in a bath of water for approximately $33 \mathrm{~h}$. They were then removed from the bath, and resistance readings and weight measurements were taken every $20 \mathrm{~min}$ on day one and every $60 \mathrm{~min}$ on day two. The block was then oven dried for $24 \mathrm{~h}$ at $65.5^{\circ} \mathrm{C}\left(150^{\circ} \mathrm{F}\right)$ and then an additional $24 \mathrm{~h}$ at $102^{\circ} \mathrm{C}\left(215^{\circ} \mathrm{F}\right)$. By use of the oven dry weight, the saturated weight (immediately after removing from bath), and the intermediate weights, the moisture content of the block was calculated over time. The resistance readings were then compared to the block moisture content. There was substantial variability in the installation methods; however, it was concluded that the graphite rod with epoxy and paste on the perimeter but not on the bottom of the rods gave the most consistent results and showed a general increase in resistance as the block dried out. Other installations either did not show a steady increase or the presence of a galvanic potential was evident from negative resistance readings. 
Resistance readings were taken with a multimeter in the $30 \mathrm{Mohm}$ manual range. To take a reading, the negative lead was connected to one probe, the wires from the probes were touched together for approximately $5 \mathrm{~s}$ to drain the charge, the positive lead was then connected to the second probe, and the reading was taken for approximately $10 \mathrm{~s}$ after connecting the second lead. Part-way through data collection, voltage readings across the probes were also collected. After taking the resistance reading, the leads were left attached, and the multimeter was adjusted to take the voltage reading.

It was found that a voltage was present between the two probes, which indicated the charging of a capacitor. Therefore, this procedure demonstrated that the standard transient approach to measuring impedance (such as used typically in wood moisture probes) is not effective in a parallel R-C circuit with a significant dielectric constant (such as masonry) as it produces unsteady readings in compliance with standard R-C circuit theory. Hence, we developed the constant voltage approach described above, which yields steady monotonically increasing resistance readings with decreasing masonry block moisture content. This approach will be implemented at the CRRF using a dedicated, linear, constant voltage power supply for each sensor to eliminate cross-talk between sensors in a conducting medium (wet masonry block). A suitable low-cost (about \$10/channel) power supply has been designed but not yet fabricated.

\subsection{STATUS OF PROJECT ON SEPTEMBER 16, 2012}

The installation used for the concrete block moisture sensors was tested in the laboratory prior to construction. Various installation methods were tested to establish the system described in Section 4.4. Testing also verified that the resistance of the concrete block varies with the moisture content of the block and that the sensors will be able to identify at a minimum whether the experimental wall is wet or dry. A trial calibration using the constant voltage methodology has verified the stability and monotonic change of resistance with moisture content. A full calibration using this methodology will allow its overall accuracy to be determined.

Installation of sensors to detect exterior temperature, block moisture content, and soil moisture content has been completed. The soil containment structures were installed and backfilled with the desired imported soils. The remaining portion of the site was backfilled with native soils and regraded. Samples of the imported soils were taken and will be delivered to a laboratory for classification using test method ASTM D422. Holes were cored in the building wall at the level of the rim joists for the installation of electrical conduit boxes and for routing all the exterior sensor wires into the basement.

On the interior of the basement wall, the waterproofing membrane, insulation, and stud frames were installed. The humidity sensors in the core of the concrete block wall were installed along with the temperature, humidity, block moisture content, and heat flux sensors that are located between the interior WSP and the insulation. All of the temperature sensors and half of the humidity sensors on the face of the insulation were installed, and some the wires still need to be routed to the top of the wall. The remaining temperature and humidity sensors are complete and ready for connection to the data acquisition system. The thermocouple reference box for each wall was wired and installed.

The remaining interior temperature and humidity sensors need to be installed and associated wires routed to the top of the wall. The gypsum also needs to be installed. All the wires from the sensors need to be wired back to the central data acquisition system. The concrete block moisture sensors need to be calibrated with a test block in the laboratory per the method described in Section 4.4. The dedicated power supplies required for each sensor need to be fabricated. 
A water spray system needs to be installed at the exterior soil enclosures. Since the system will only be used during the cooling season (May-September) and the lines will not be insulated, this will be completed in the spring of 2013.

The CRRF data acquisition system is being completely renovated in parallel with (but separate from) this project as its initial configuration developed in 1997 has become completely obsolete and unreliable owing to the age of the computers (1996 vintage). The system is being converted to a state-of-the-art deterministic real-time configuration with distributed processing. The revised system has been configured in the laboratory and has been tested for functionality. Currently, a distributed operating system based on the current revision (2012) of the National Instruments LabView Real Time development platform is being ported to the CRRF system. This is proprietary software that already has successfully completed extensive field testing and is based on a TCP/IP implementation of the VPI (vector priority interrupt) software architecture pioneered at the University of Minnesota's Foundation Test Facility in the late 1980s. Porting such complex code always is challenging and this is no exception; already, bugs in the 2012 LabView development platform have been discovered and, in consultation with application engineers from National Instruments, are being resolved.

\subsection{PROJECTED OUTCOME}

The goal of the project is to generate a transient hygrothermal data set per Fig. 6 and Section 4.3 for two quite different soil types (silt/clay and sand) on full basement masonry block walls with both north and south exposures for a full calendar year. These data will be stored at 20 minute increments and can be used as a basis against which the output from a foundation hygrothermal simulation analysis can be compared using the measured interior and exterior boundary conditions to drive the simulation. 

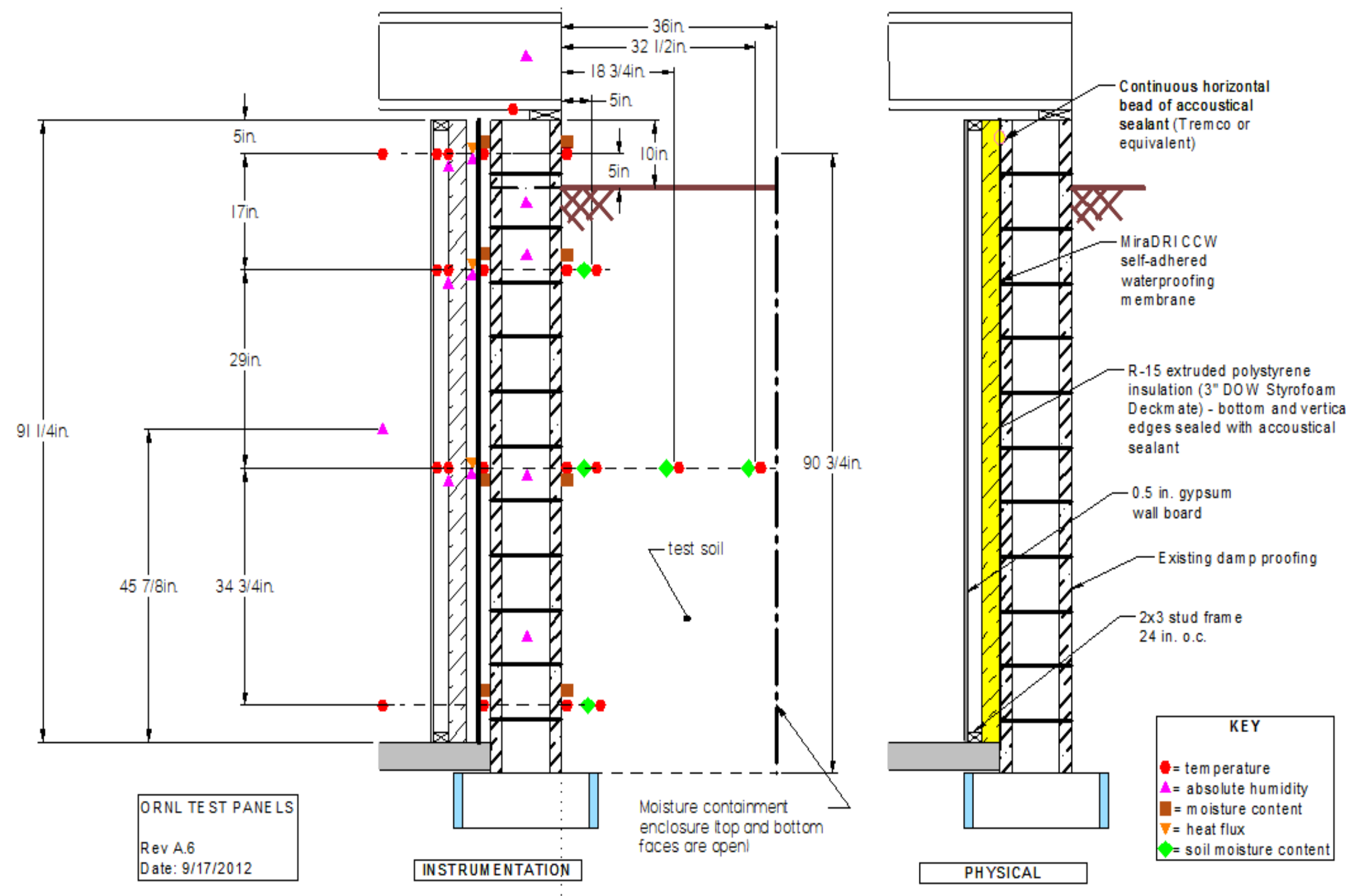

Fig. 6. Schematic design of test panels and associated instrumentation. 


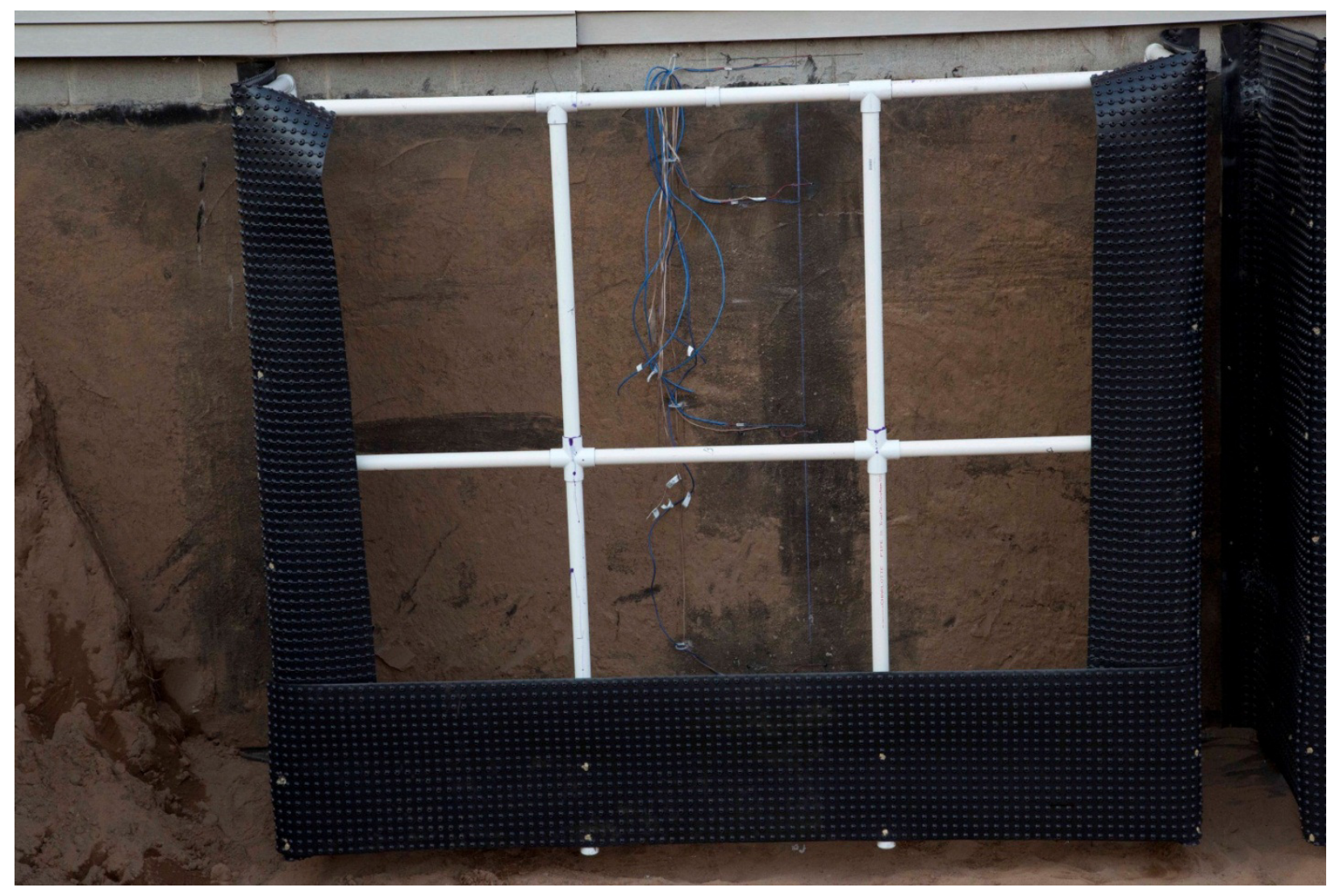

Fig. 7. Exterior soil containment and sensors. 


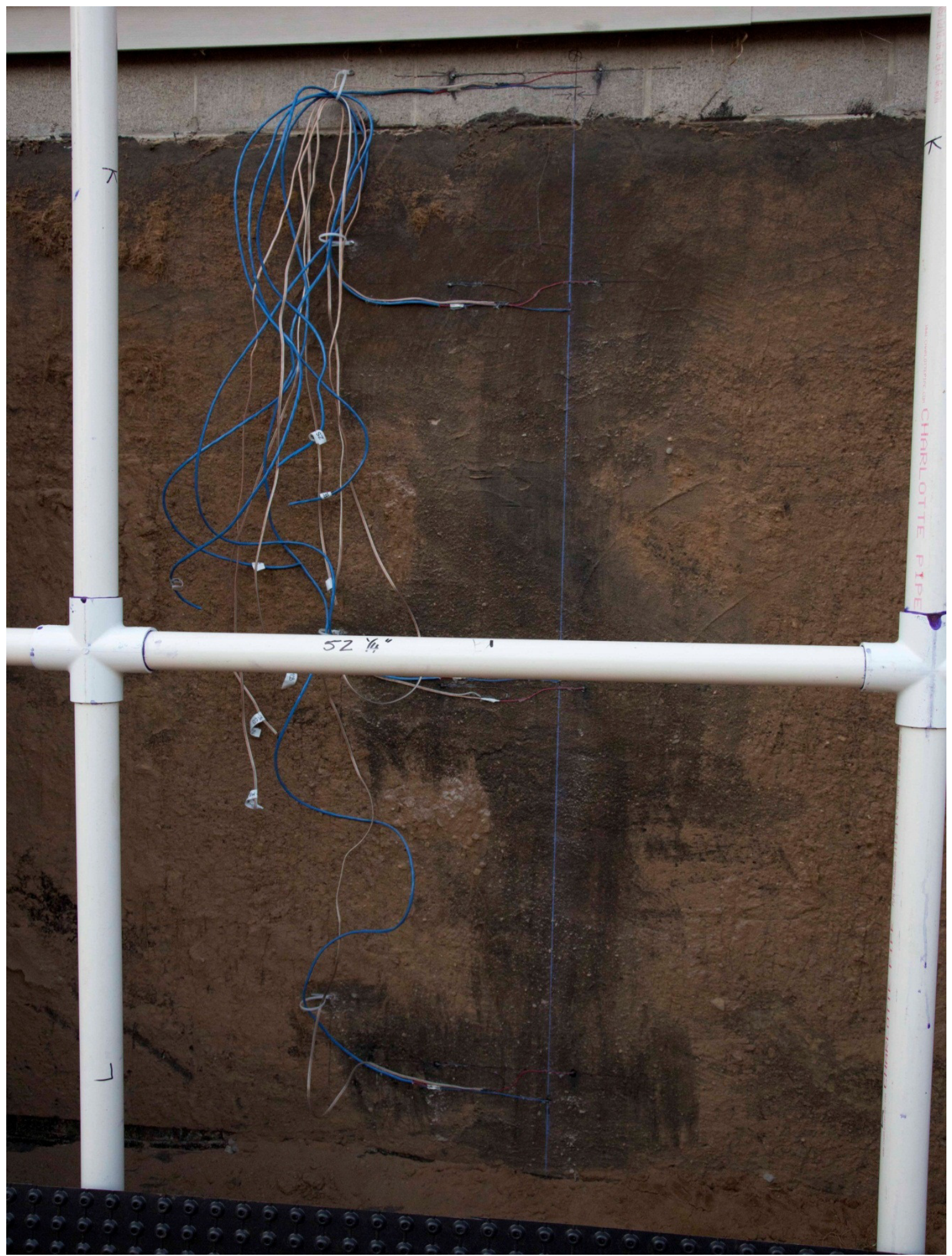

Fig. 8. Exterior sensors (block moisture content and temperature). 


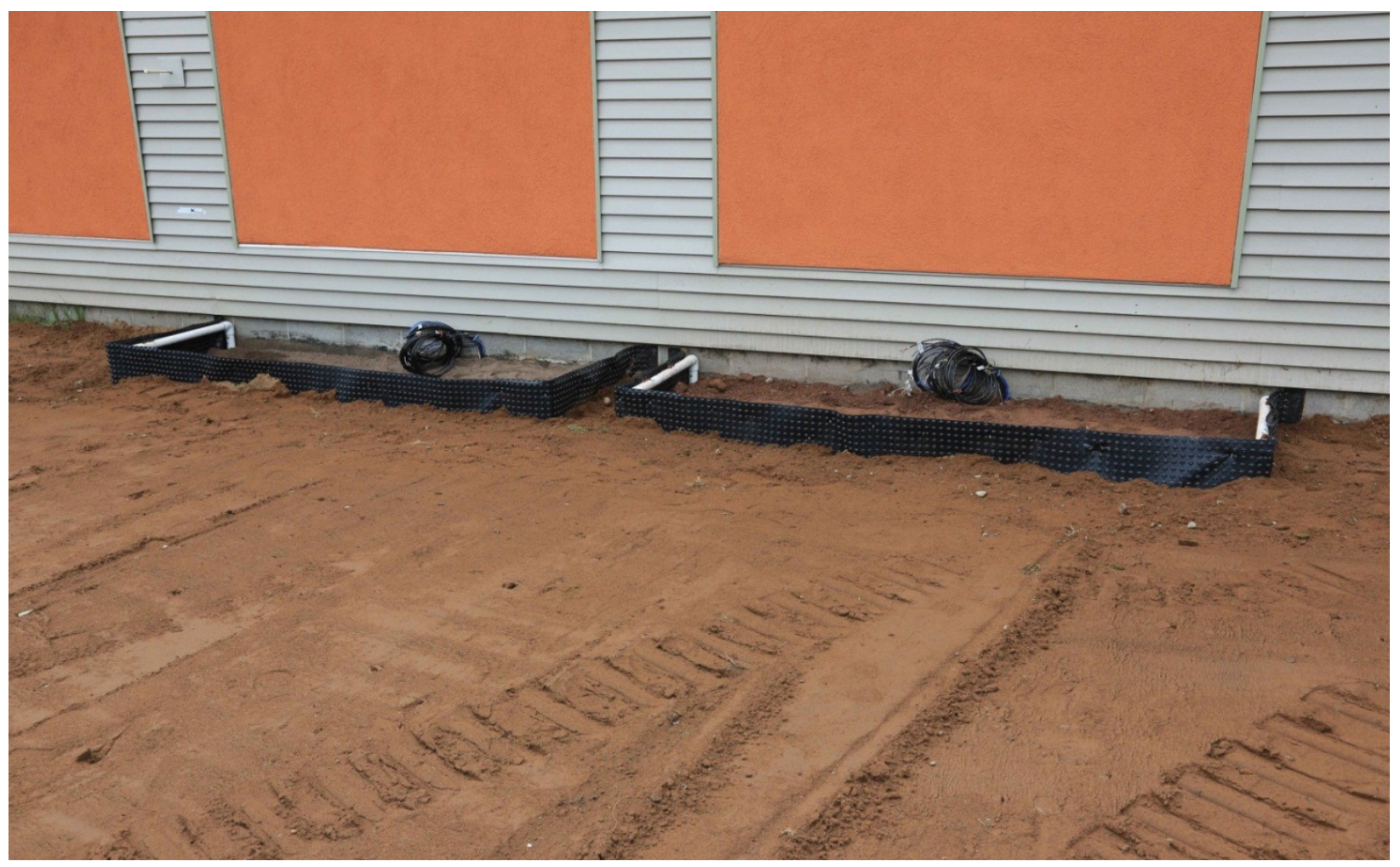

Fig. 9. Backfilled exterior soil containment. 


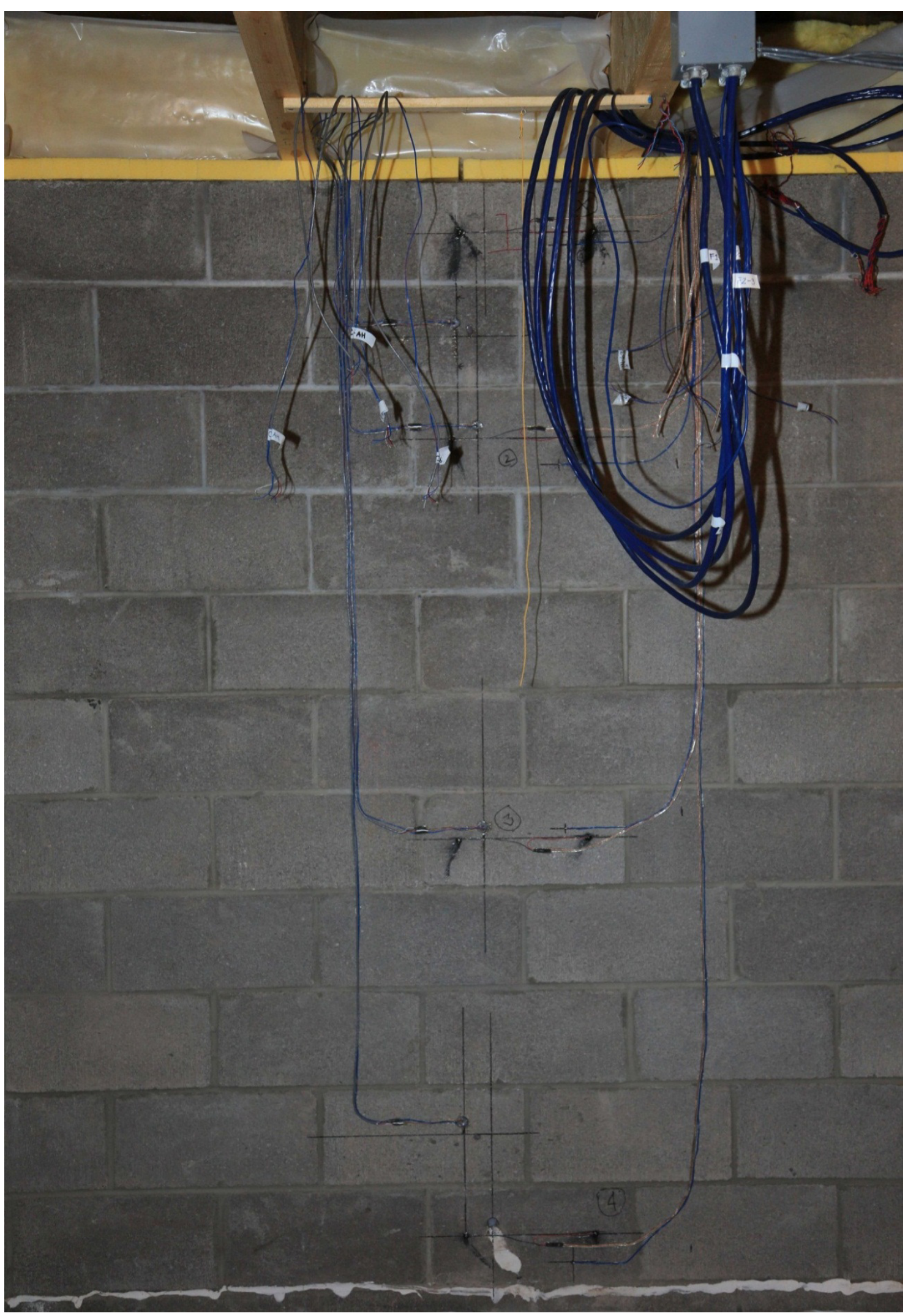

Fig. 10. Interior block wall sensors (block moisture content, humidity, and temperature). 


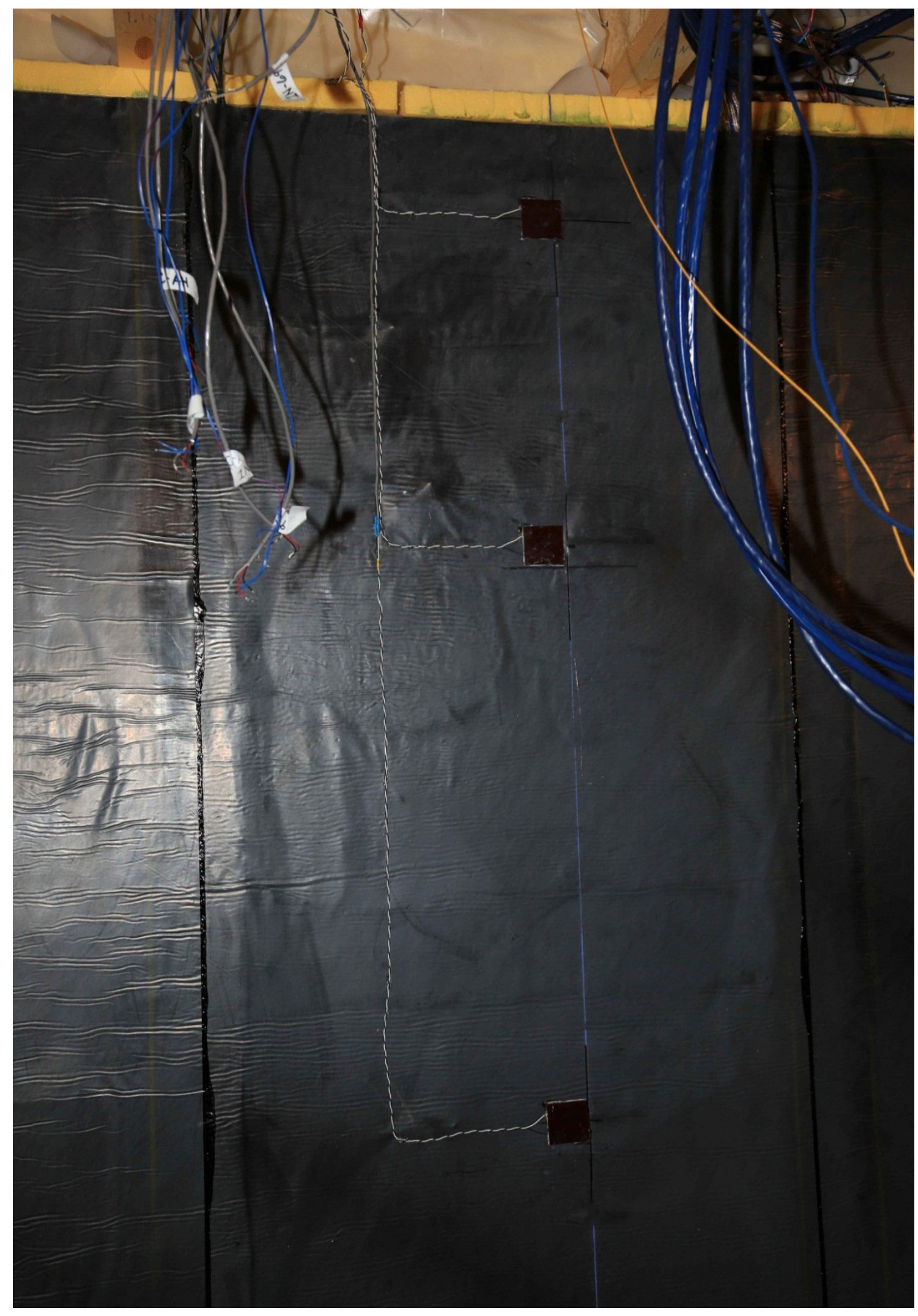

Fig. 11. Interior WSP sensors (heat flux plates). 


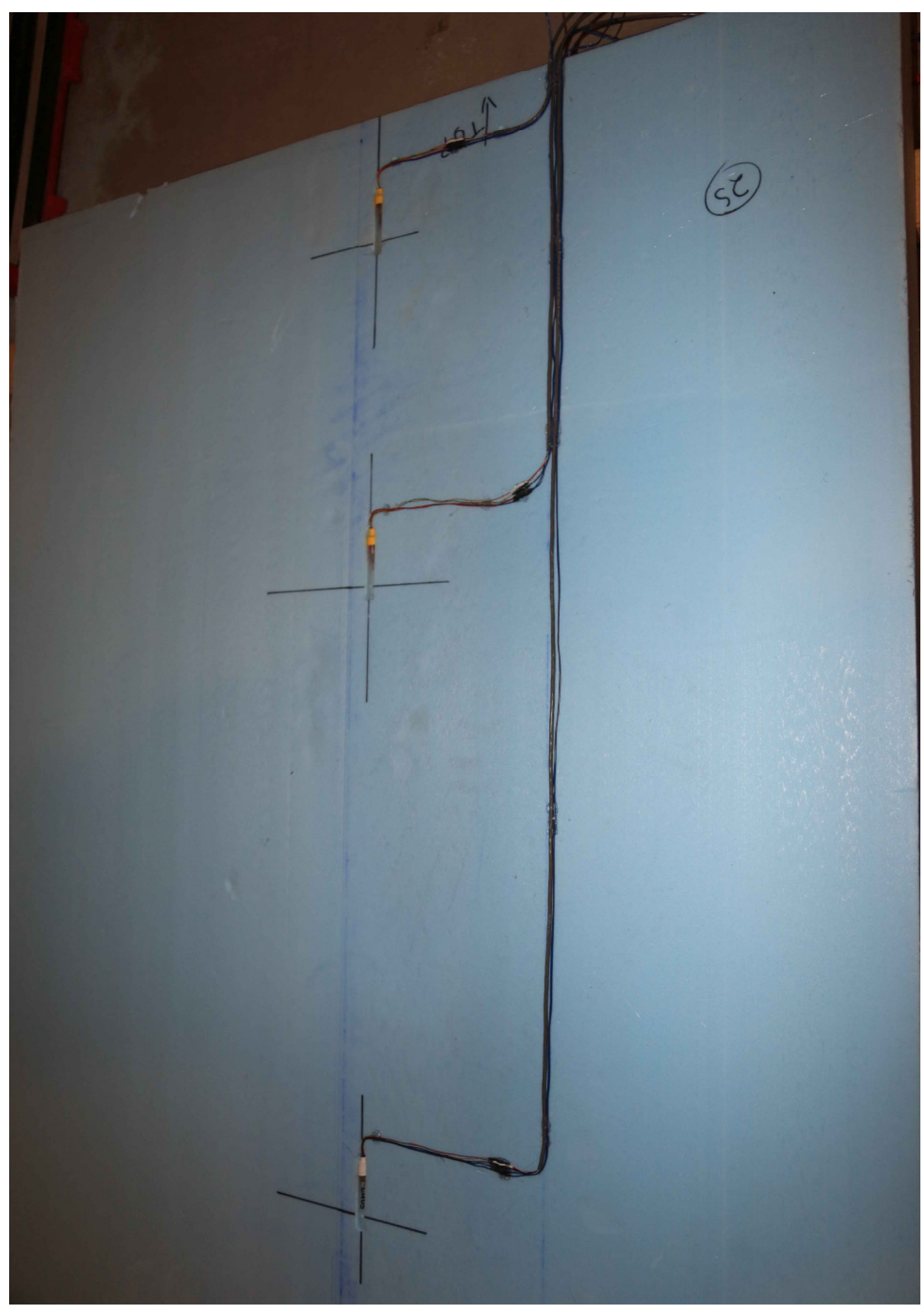

Fig. 12. Humidity sensors pocketed in back of insulation. 


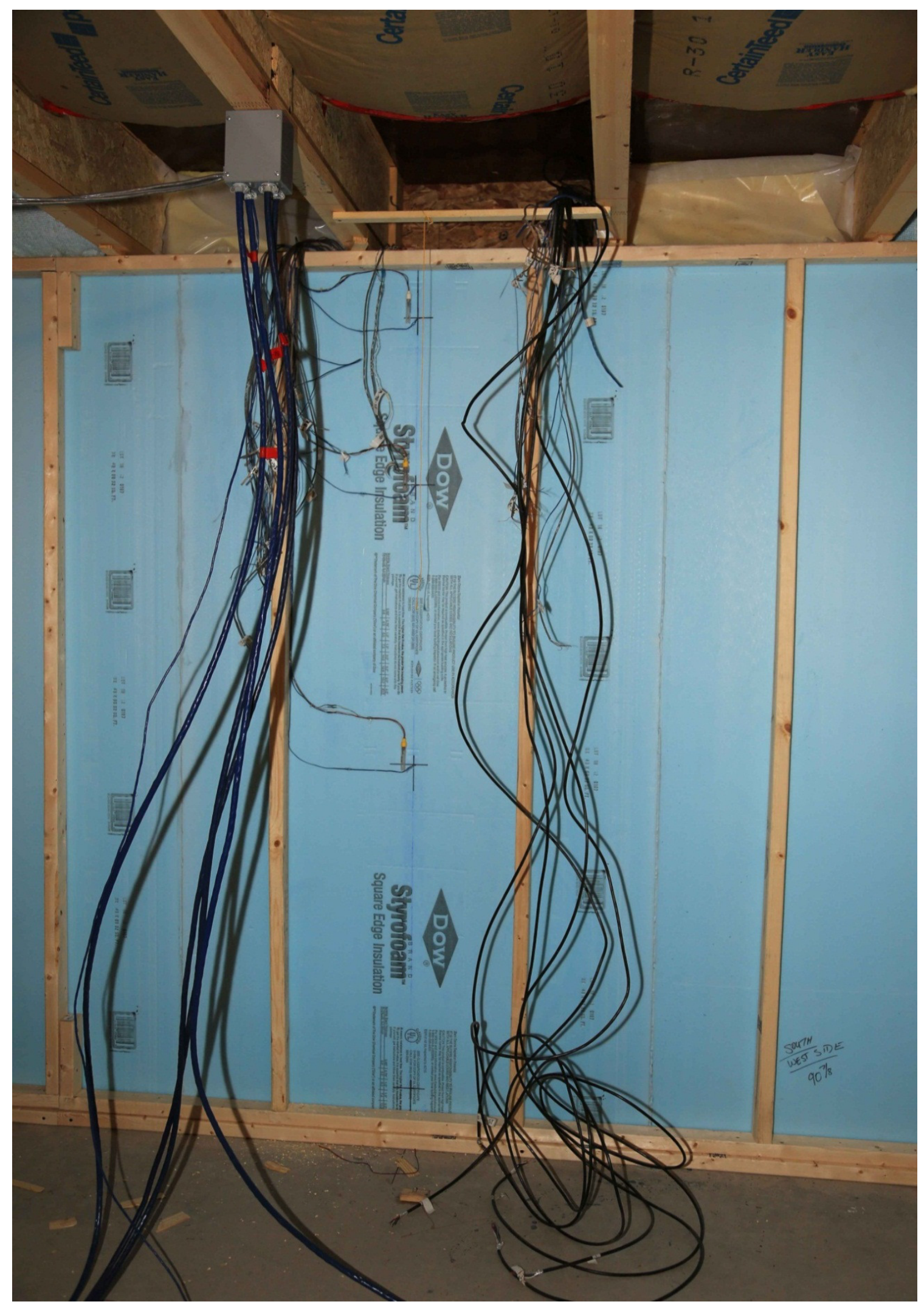

Fig. 13. Interior face of insulation sensors (humidity and temperature). 


\section{DISCUSSION AND CONCLUSION}

The intentions of the first part of this study have been fulfilled. The soil properties of interest in Building Science have been defined for 12 different soil textures. These properties will serve as input parameters when performing hygrothermal calculations of building constructions coupled to soil materials. The reliability of the soil parameters will be further evaluated with measurements in Part 2.

The moisture storage capacity, $w$, ranges from $49 \mathrm{~kg} / \mathrm{m}^{3}$ in loamy sand and $138 \mathrm{~kg} / \mathrm{m}^{3}$ in sandy clay to $375 \mathrm{~kg} / \mathrm{m}^{3}$ in sand and $489 \mathrm{~kg} / \mathrm{m}^{3}$ in silt. In sand, the moisture storage capacity increases insignificantly for relative humidity below $99.8 \%$, which makes sand nonhygroscopic. Loamy sand shows similar behavior as sand with regard to the moisture storage function. Of the 12 defined soil textures, the moisture storage capacity increases most rapidly for clay.

The liquid diffusivity must be distinguished into two types, wetting and drying diffusivities, of which the latter is usually a little smaller. The drying diffusivity is commonly measured and expressed in existing literature; hence a relation factor for the wetting diffusivity has been established and applied in this study.

The thermal conductivities for clay, sand, and silt have been defined in existing studies. The other nine defined soil textures have been estimated by combining the thermal conductivities of these three soil components.

The comparison of measured and simulated ground temperature at the depth of $1 \mathrm{~m}$ shows rather good agreement though improvements to the simulation model are required. Currently, WUFI does not allow full absorption of precipitation at the surface border if the outer element is moisture saturated. Further, the moisture transfer at the lower boundary (i.e., the border representing the infinite ground) should be improved to better simulate the existing moisture transfer mechanisms at this border. Consequently, changes in the existing software code WUFI must be implemented to consider the effects discussed regarding liquid uptake of precipitation and liquid flow through and out of the simulated system.

The heat transfer coefficient at the soil surface varies with a number of factors that are not yet included in the simulation model. Once these improvements are implemented, the simulations results are more likely to better fit the measurements. An example of a factor not yet included is the effect on the wind-driven heat transfer coefficient resulting from the texture of the grass and the influence of surrounding objects. In addition, snow coverage of the ground, along with its effect on the surface thermal resistance and longand short-wave radiation, has not been taken into account.

\section{REFERENCES}

Abu-Hamdeh, N. H. 2003. "Thermal properties of soils affected by density and water content," Biosyst. Eng. 86(1), 97-102; doi: 10.1016/s1537-5110(03)00112-0.

Acs, F., D. Mihailovic, and B. Rajkovic. 1990. "A coupled soil moisture and surface temperature prediction model," J. Appl. Meteorol. 30(6).

Becker, R. B., and B. A. Fricke. 1997. Effects of Saturation and Dry Density on Soil Thermal Conductivity, Department of Mechanical and Aerospace Engineering, University of Missouri-Kansas City.

Blanco-Canqui, H., R. Lal, W. M. Post, R. C. Izaurralde, M. J. and Shipitalo. 2006. "Organic carbon influences on soil particle density and rheological properties," Soil Sci. Soc. Am. J. 70(4), 1407-1414. 
Davies, M. and Z. Ye, 2009. “ A 'pad' sensor for measuring the moisture content of building materials," Build. Serv. Eng. Res. Technol. 30(3), 263-270.

Duble, R. 2011. “Introduction, Soil Texture Triangle," in Turfgrass Rootzones, retrieved June 11, 2012, http://www.turfdiag.com/turfgrassrootzones.htm .

EN 12524. 2000. Wärme- und feuchteschutztechnische Eigenschaften Tabellierte Bemessungswerte Baustoffe und -produkte: Deutsche Norm [building materials and products, hygrothermal properties, tabulated design values].

EN ISO 13370:2007. 2007. Thermal performance of buildings, heat transfer via the ground, calculation methods; TC 163, thermal performance and energy use in the built environment; TC 163/SC 2, Calculation methods, European standard.

Eshel, G., G. J. Levy, U. Mingelgrin, and M. J. Singer. 2004. "Critical evaluation of the use of laser diffraction for particle-size distribution analysis," Soil Sci. Soc. Am. J. 68(3), 736-743.

Goldberg, L. F., and B. Steigauf, 2011. Cold Climate Foundation Retrofit Energy Savings: The Simulated Energy and Experimental Hygrothermal Performance of Cold Climate Foundation Wall Insulation Retrofit Measures - Phase I, Energy Simulation, research report prepared for Building America Building Technologies Program, Office of Energy Efficiency and Renewable Energy, US DOE, under subcontract no. KNDJ-0-40338-02.

Gopalakrishnan, K., and A. Manik. 2007. "A mathematical model for predicting isothermal soil moisture profiles using finite difference method," Int. J. Comput. Math. Sci. 1(2).

Hagentoft, C.-E. 2001. Introduction to Building Physics, Studentlitteratur , Lund, Sweden.

Heidreich, U. 2006. "Nutzung oberflächennaher Geothermie zum Heizen und Kühlen eines Bürogebäudes," presented at the Symposium Energetische Sanierung von Schul- und Verwaltungsgebäuden, FH Münster.

Hills, R. G., D. B. Hudson, I. Porro, and P. J. Wierenga. 1989. "Modeling one-dimensional infiltration into very dry soils, 2. Estimation of the soil-water parameters and model predictions," Water Resour. Res. 25(6), 1271-1282; doi: 10.1029/WR025i006p01271.

Janssen, H., J. Carmeliet, and H. Hens, H. 2004. "The influence of soil moisture transfer on building heat loss via the ground," Build. Environ. 39(7), 825-836; doi: 10.1016/j.buildenv.2004.01.004.

Keller, T., and I. Håkansson. 2010. "Estimation of reference bulk density from soil particle size distribution and soil organic matter content," Geoderma 154(3-4), 398-406; doi:

10.1016/j.geoderma.2009.11.013.

Khoshbakht, M., and M.W. Lin. 2006. "Development of an electrical time domain reflectometry (ETDR) distributed moisture measurement technique for porous media," Meas. Sci. Technol. 17(11), 2989.

Kiessl, K., and K. Gertis. 1980. Feuchtetransport in Baustoffen: Eine Literaturauswertung zur rechnerischen Erfassung hygrischer Transportphänomene, Universität Essen Gesamthochschule. 
Kim, H., S. H. Anderson, P. P. Motavalli, and C. J. Gantzer. 2010. "Compaction effects on soil macropore geometry and related parameters for an arable field," Geoderma 160(2), 244-251; doi: 10.1016/j.geoderma.2010.09.030.

Kung, S. K. J., and T. S. Steenhuis. 1986. "Heat and moisture transfer in a partly frozen nonheaving soil," Soil Sci. Soc. Am. J. 50(5), 1114-1122.

Künzel, H. M. 1995. Simultaneous Heat and Moisture Transport in Building Components, One- and TwoDimensional Calculation Using Simple Parameters, dissertation, University Stuttgart, IRB Verlag; retrieved from www.WUFI.com.

LFU Bayern. 2012. Communication between M. Kehrer and representative of Bayerisches Landesamt fuer Umweltschutz; Bodenkundliche Aufnahme (Geological Administration of Bavaria).

Mabirizi, D. 2000. Wetting and Drying Unsaturated Soil Diffusivity Measurements in Laboratory, Master's thesis, Oklahoma State University.

Mabirizi, D., and R. Bulut. 2009. Unsaturated Soil Moisture Drying and Wetting Diffusion Coefficient Measurements in the Laboratory, School of Civil and Environmental Engineering, Oklahoma State University / Oklahoma Transportation Center.

Maksimovic M., G. C. Stojanovic, M. Goran, M. Radovanovic, M. Malesev, V. Radonjanin, G. R. Fadosavljevic, and W. Smetana. 2012. "Application of LTCC sensor for measuring moisture content in building materials," Construct. Build. Mater. 26(1), 327-333.

Neto, D. D., Q. D. van Lier, M. T. van Genuchten, K. Reichardt, K. Metselaar, and D. R. Nielsen. 2011. "Alternative analytical expressions for the general van Genuchten-Mualem and van Genuchten-Burdine hydraulic conductivity models," Vadose Zone J. 10(2), 618-623; doi: 10.2136/vzj2009.0191

Noorallah, G. J. 1999. Introduction to Soil Science and Soil Resources, Vol. 1, Salman Productions Inc.

Olchev, A., K. Radler, A. Sogachev, O. Panferov, and G. Gravenhorst. 2009. "Application of a threedimensional model for assessing effects of small clear-cuttings on radiation and soil temperature," Ecol. Modell. 220(21), 3046-3056; doi: 10.1016/j.ecolmodel.2009.02.004

Prunty, L. 2009. “Soil water thermal liquid diffusivity,” Soil Sci. Soc. Am. J. 73(3), 704-706; doi: 10.2136/sssaj2008.0097

Ray, C., T. Vogel, and J. Dusek. 2004. "Modeling depth-variant and domain-specific sorption and biodegradation in dual-permeability media," J. Contam. Hydrol. 70(1-2), 63-87; doi:

10.1016/j.jconhyd.2003.08.009

Richard, G., I. Cousin, J. F. Sillon, A. Bruand, and J. Guérif. 2001. "Effect of compaction on the porosity of a silty soil: influence on unsaturated hydraulic properties (Effet du compactage sur la porosité d'un sol limoneux: conséquences sur les propriétés hydrauliques en non saturé)," Eur. J. Soil Sci. 52(1), 49-58; doi: 10.1046/j.1365-2389.2001.00357.x

Rühlmann, J., M. Körschens, and J. Graefe. 2006. "A new approach to calculate the particle density of soils considering properties of the soil organic matter and the mineral matrix," Geoderma 130(3-4), 272283; doi: 10.1016/j.geoderma.2005.01.024 
Schaap, M. G. 2002. Rosetta: A Computer Program for Estimating Soil Hydraulic Parameters with Hierarchical Pedotransfer Functions, Version 1.2, http://cals.arizona.edu/research/rosetta/rosetta.html.

Schaap, M. G., R. J. Leij, and M. T. van Genuchten. 2001. "Rosetta: a computer program for estimating soil hydraulic parameters with hierarchical pedotransfer functions," J. Hydrol. 251(3-4), 163-176; doi: 10.1016/s0022-1694(01)00466-8

Šimůnek, J., R. Kodešová, M. M. Gribb, and M. T. van Genuchten. 1999. "Estimating hysteresis in the soil water retention function from cone permeameter experiments," Water Resour. Res. 35(5), 1329_ 1345; doi: 10.1029/1998wr900110

Staszczuk, A., J. Radon, and A. Holm. 2010. "Evaluation of simplified calculation method of heat exchange between building and ground," presented at CESBP 2010, Central European Symposium on Building Physics, Krakow, International Association of Building Physics.

USDA. 2008. "Bulk density," p. 2 in Soil Quality Indicators, Natural Resources Conservation Service, US Department of Agriculture.

van Genuchten, M. T. 1980. "A closed-form equation for predicting the hydraulic conductivity of unsaturated soils," Soil Sci. Soc. Am. J. 44(5), 7.

Zhou, J., and Yu, J.-L. 2005. "Influences affecting the soil-water characteristic curve," J. Zhejiang Univ. 6(8), 8 . 
APPENDIX A. Moisture Storage Functions Based on Eq. (11)

Moisture storage function - Texture class 1 to 4

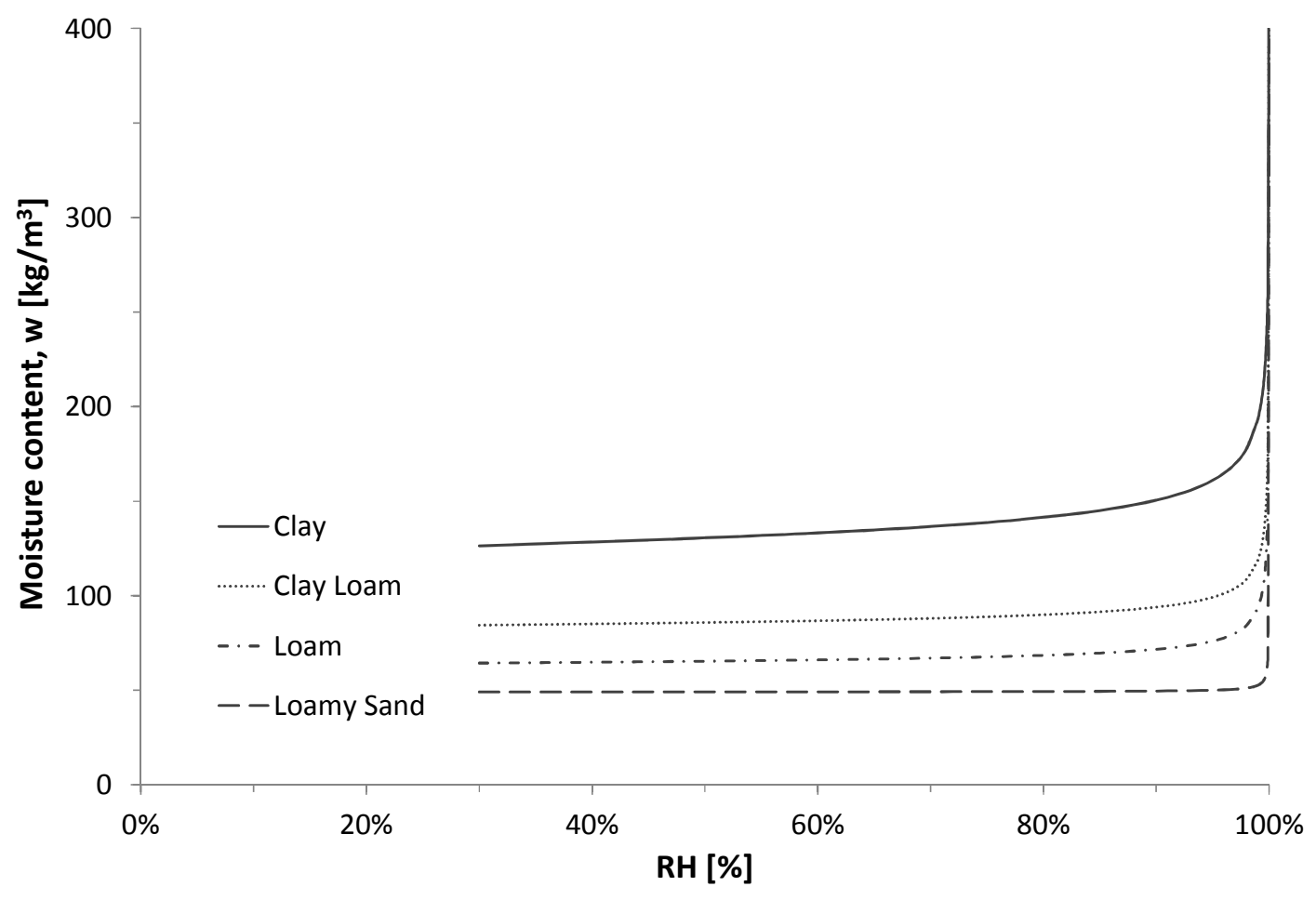

Moisture storage function - Texture class 5 to 8

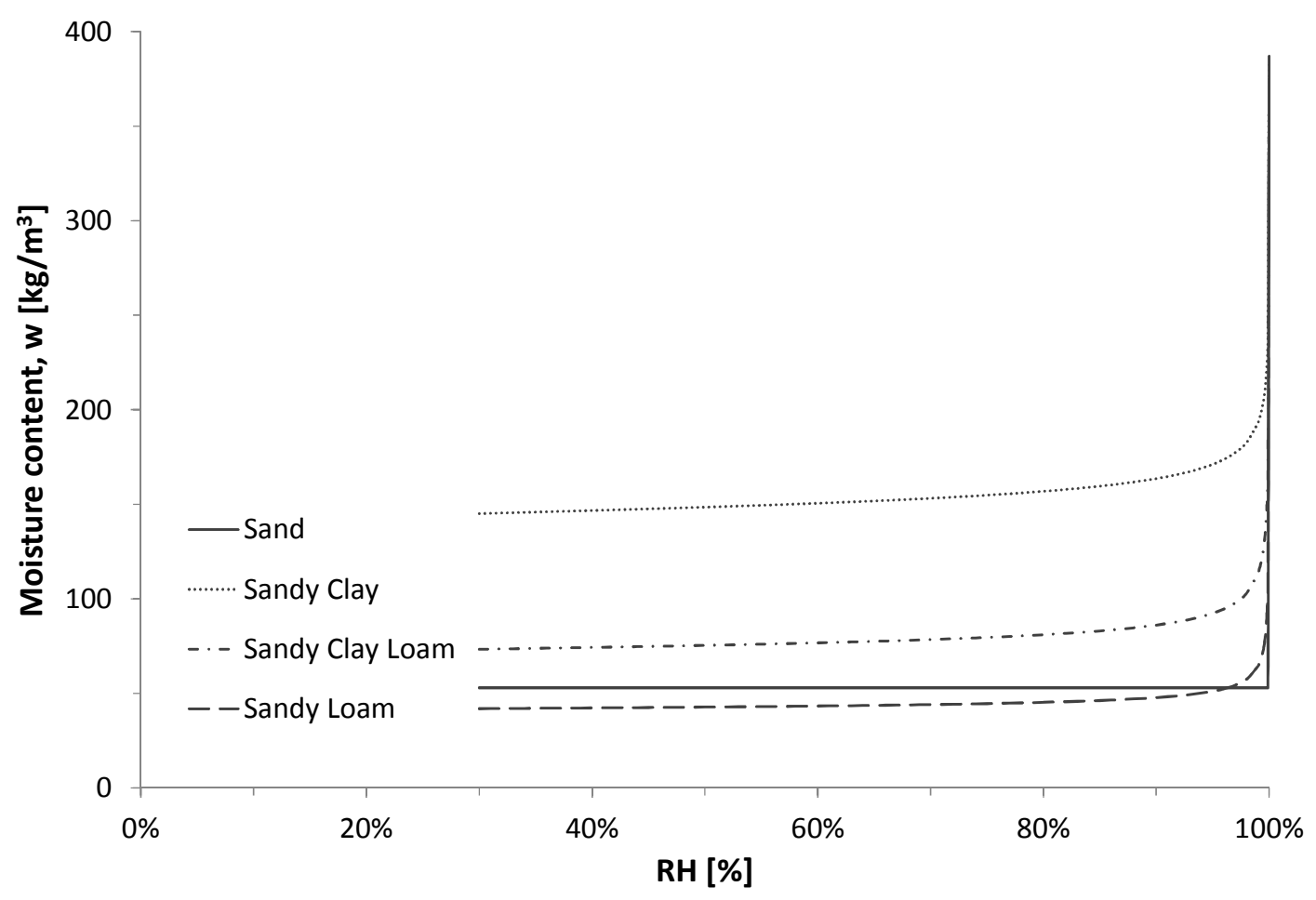


Moisture storage function - Texture class 9 to 12

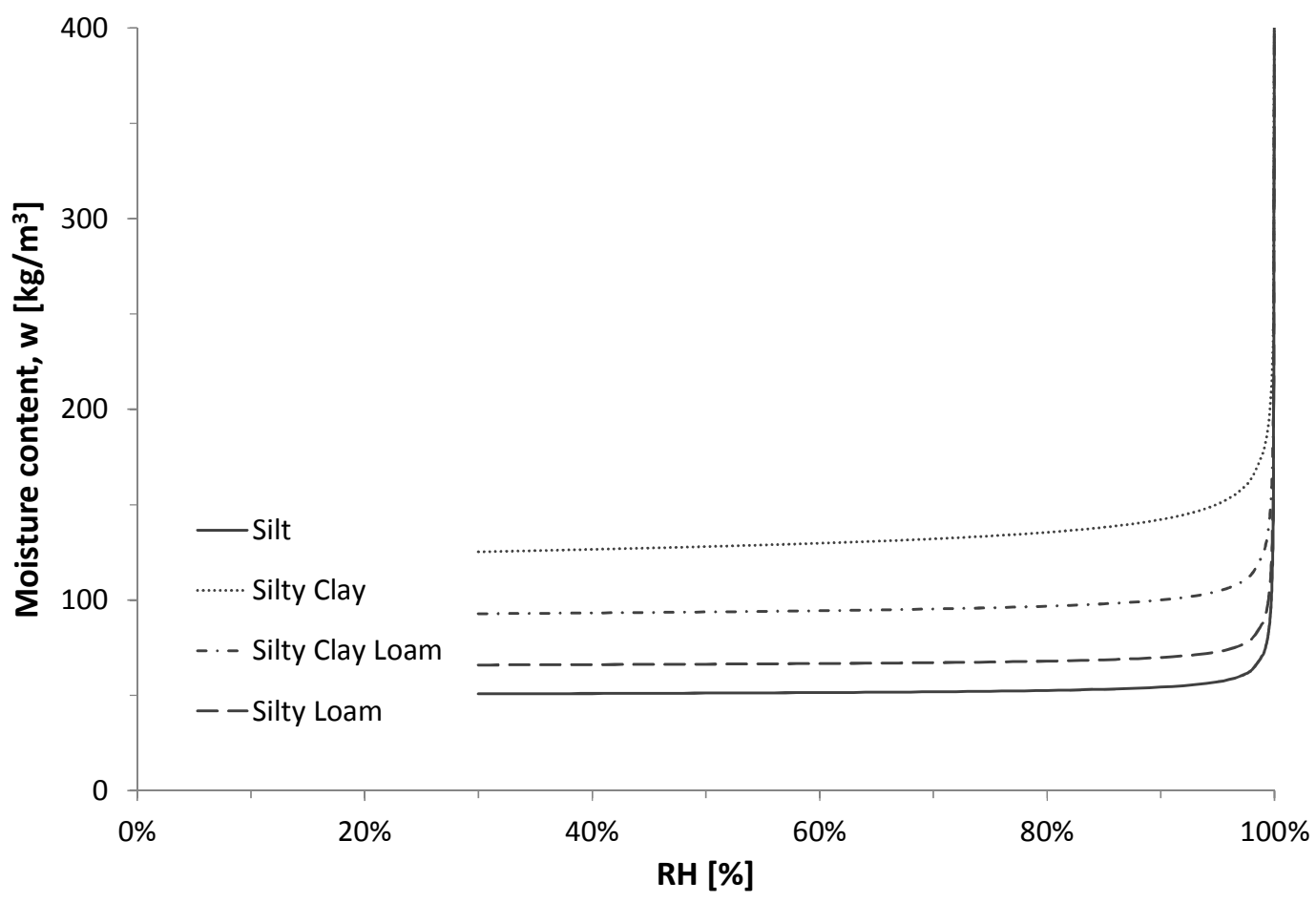




\section{APPENDIX B. $D_{d r y}$ Values for All Soil Texture Classes and $D_{w e t}$ Values for Clay and Silt}
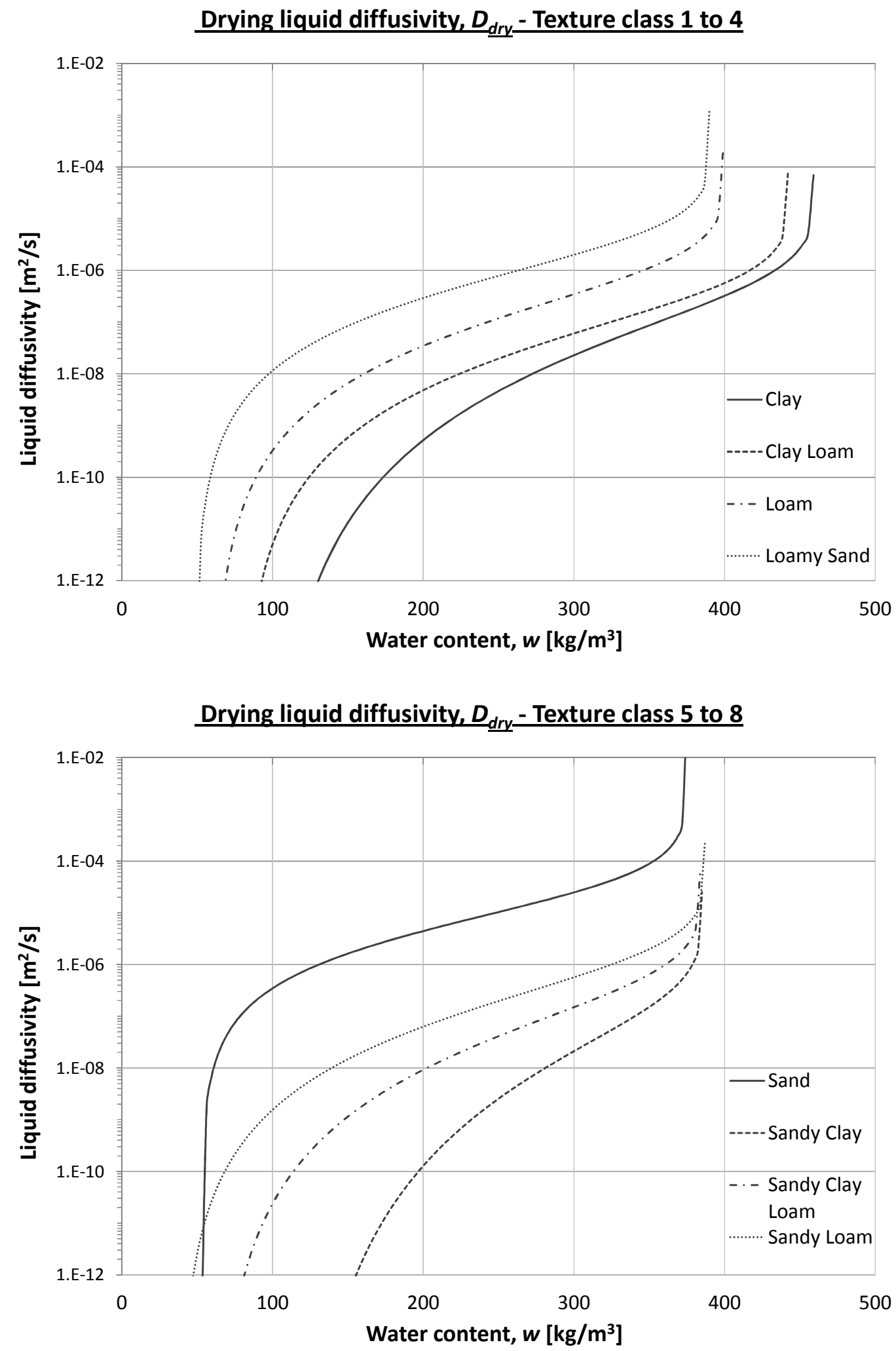


\section{Drying liquid diffusivity, $D_{d r y}$ - Texture class 9 to 12}

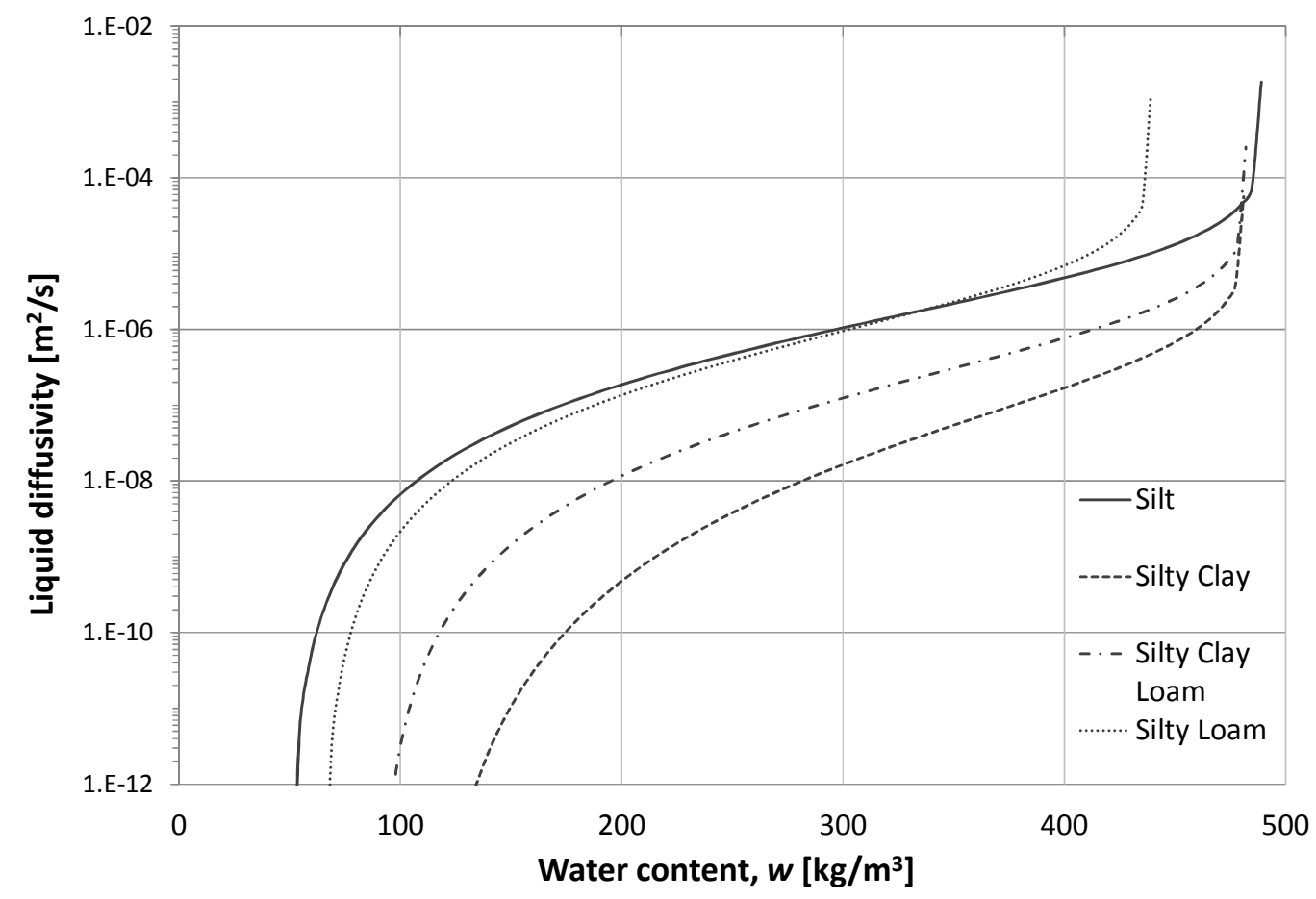

Drying and Wetting liquid diffusivity - Clay and Silt

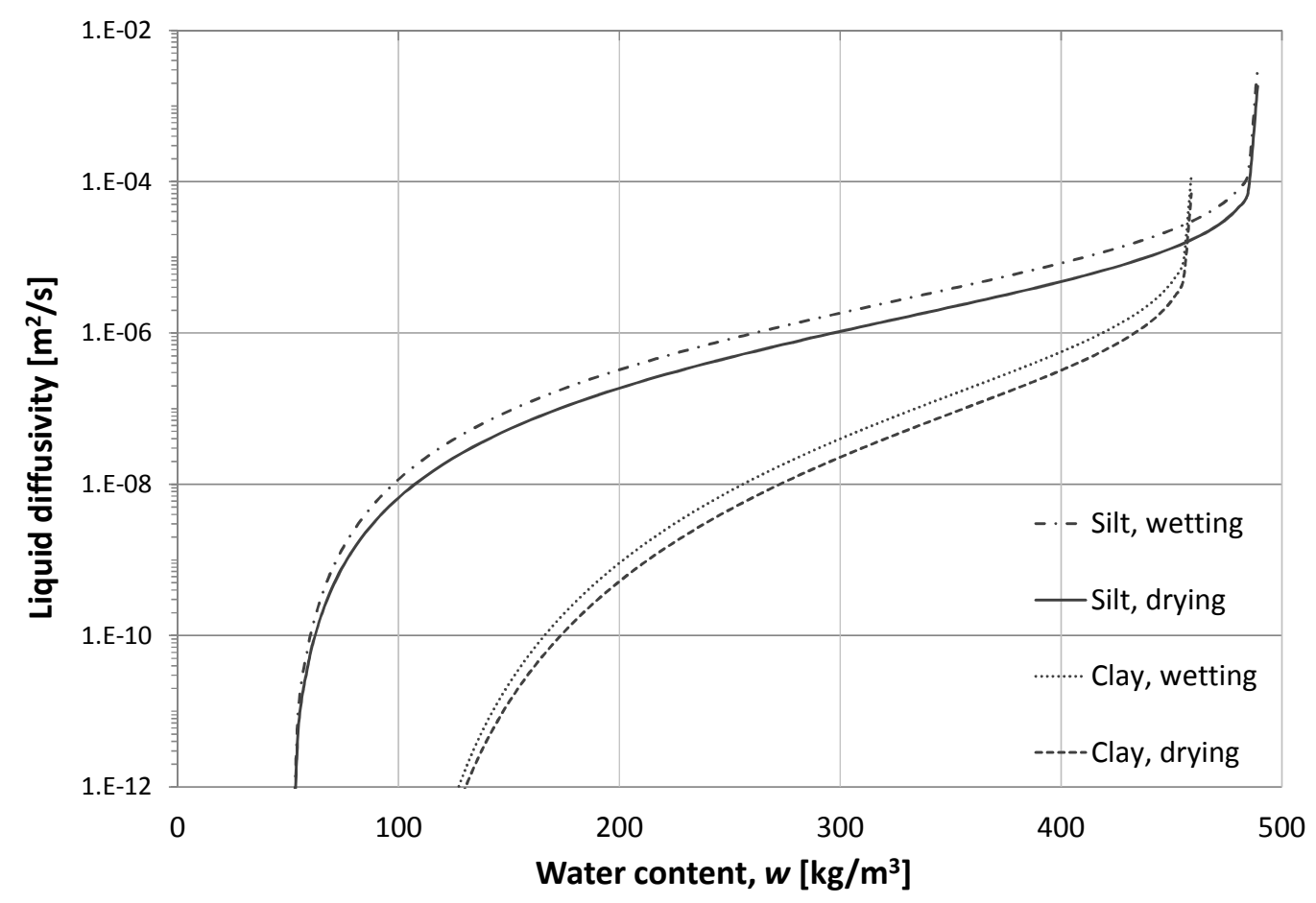




\section{APPENDIX C. Soil Thermal Conductivities as a Function of Water Content}

from Eq. (20) for Clay, Sand, and Silt

Thermal conductivity as a function of water content - Clay

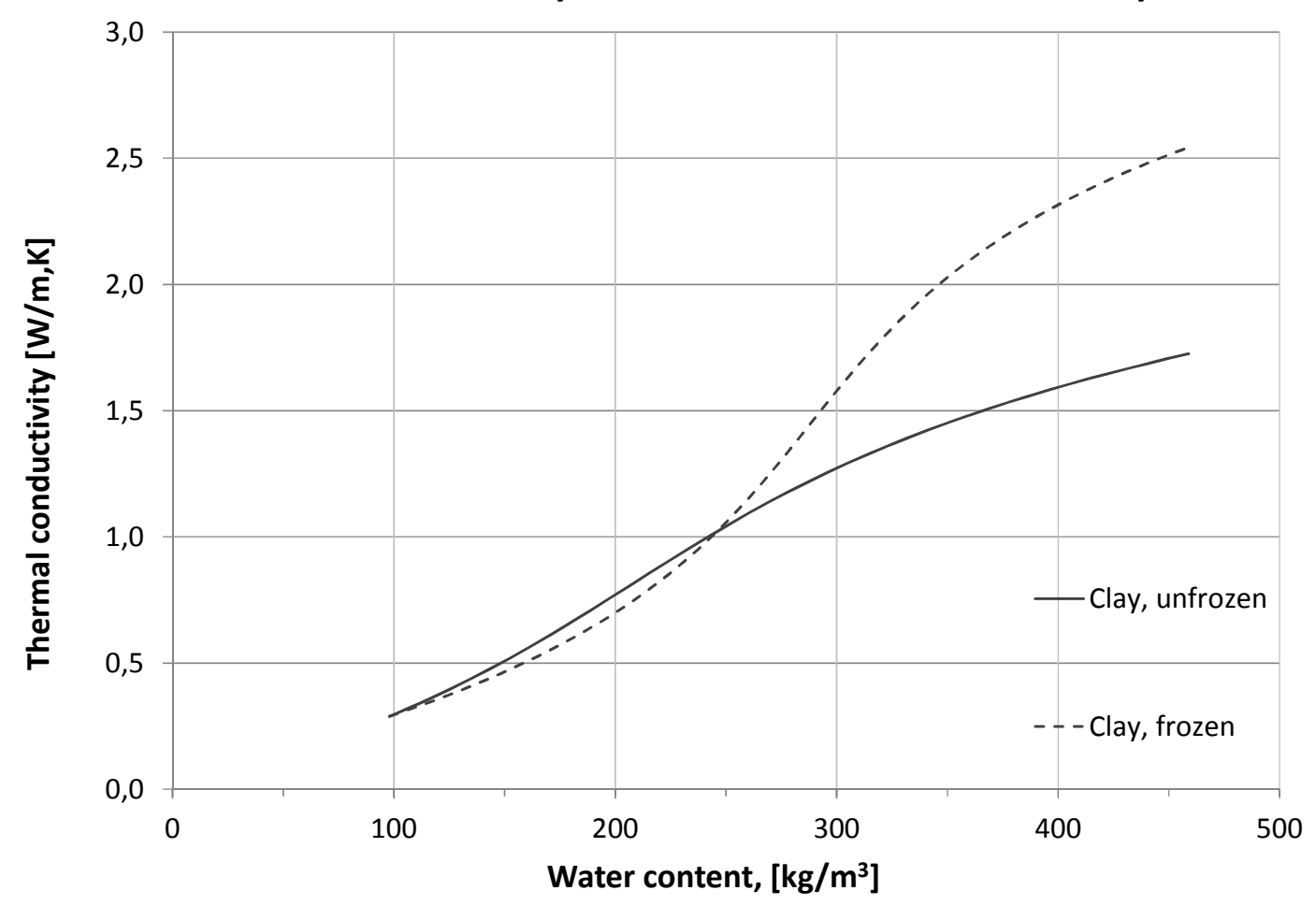

Thermal conductivity as a function of water content - Sand

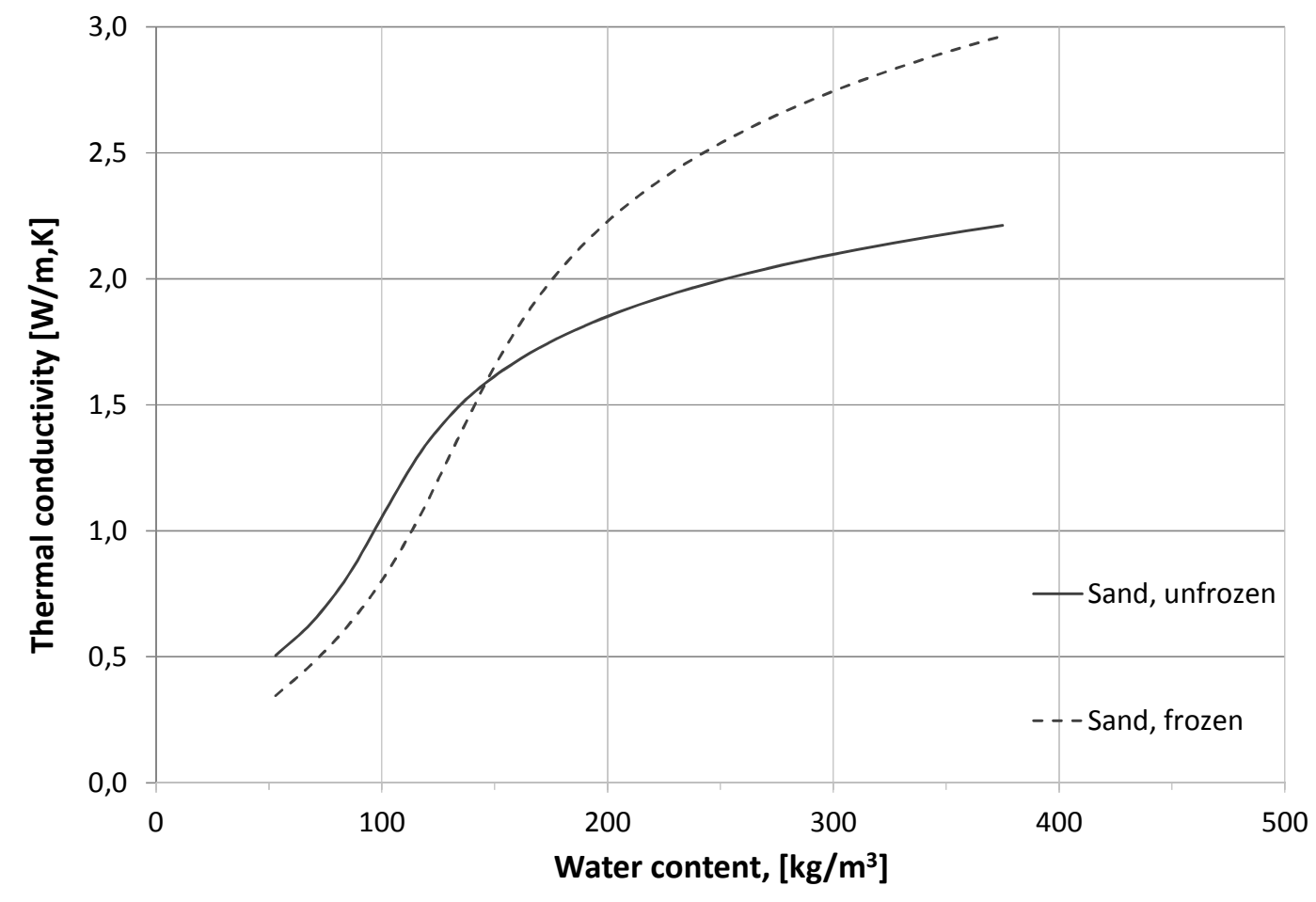


Thermal conductivity as a function of water content - Silt

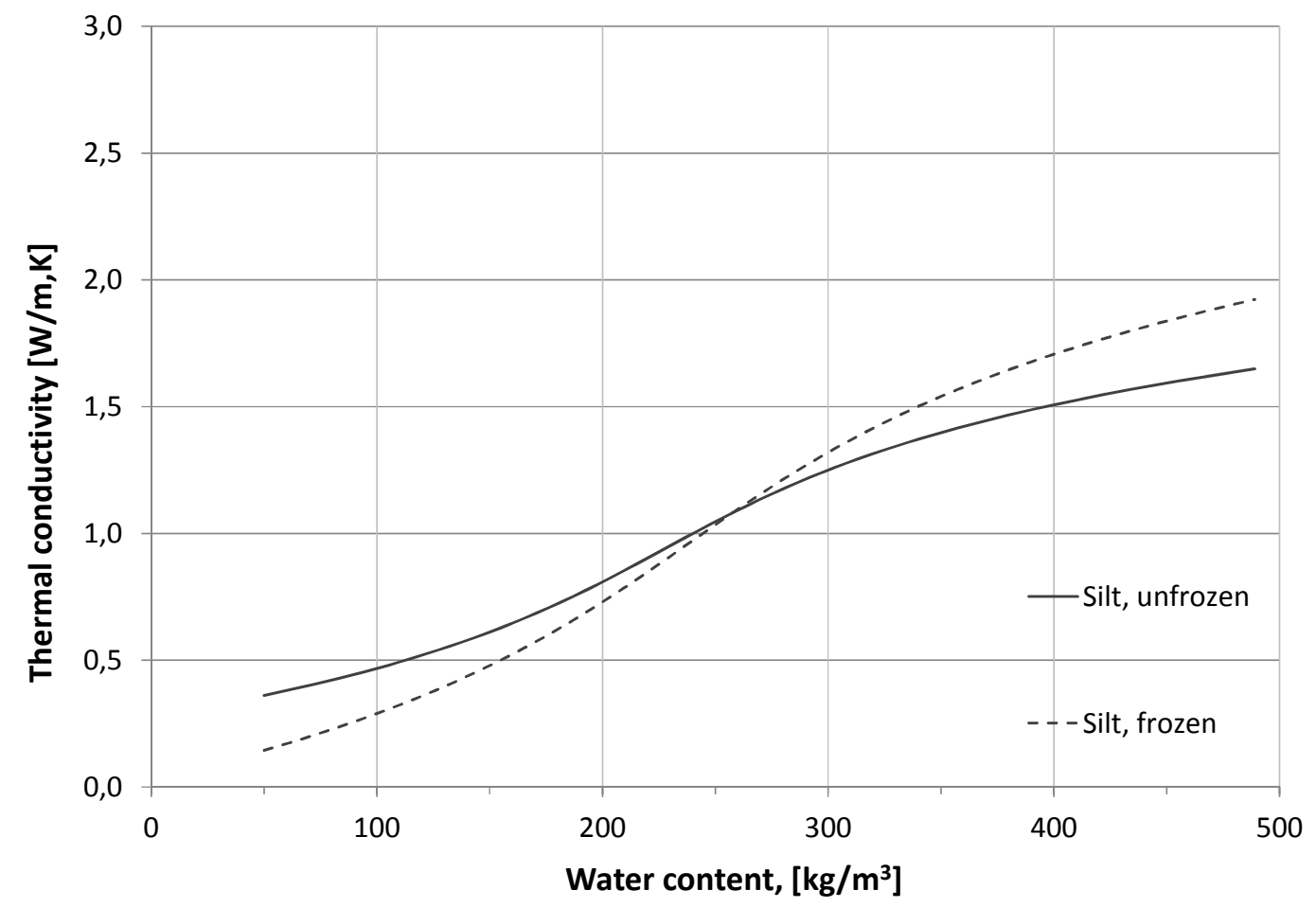




\section{APPENDIX D. Compositions of the 12 USCS Soil Textures and Their Thermal Conductivities}

Estimated compositions of the 12 soil textures defined by the Unified Soil Classification System (USDA, 2008) are listed in the following table

\begin{tabular}{lccc}
\hline & \multicolumn{3}{c}{ Portion of $(\%)$} \\
\cline { 2 - 4 } \multicolumn{1}{c}{ Composition } & Clay, $\boldsymbol{P}_{\text {clay }}$ & Sand, $\boldsymbol{P}_{\text {sand }}$ & Silt, $\boldsymbol{P}_{\text {silt }}$ \\
\hline Average & & & \\
Clay & 60 & 20 & 20 \\
Sand & 5 & 90 & 5 \\
Silt & 8 & 8 & 84 \\
Estimated & & & \\
Clay loam & 35 & 30 & 35 \\
Loam & 18 & 42 & 40 \\
Loamy sand & 7 & 82 & 11 \\
Sandy clay & 40 & 52 & 8 \\
Sandy clay loam & 27 & 58 & 15 \\
Sandy loam & 10 & 65 & 25 \\
Silty clay & 47 & 7 & 46 \\
Silty clay loam & 34 & 10 & 56 \\
Silt loam & 15 & 20 & 65 \\
\hline
\end{tabular}

The soil thermal conductivities as a function of water content, $k(w)$, have been estimated for clay, sand, and silt. The thermal conductivities of the other nine soil textures are estimated by use of a system of linear equations described here.

If clay, sand, and silt are considered to be the components of the 12 soil textures, then let

$$
\text { clay }=X \text {, sand }=Y \text {, and silt }=Z \text {. }
$$

The three principal soil textures—clay, sand, and silt—can described as proportions of the components $X$, $Y$, and $Z$; hence, the soil compositions (according to the upper part of the table above) are as follows:

$\begin{array}{lr}\text { Clay }=\quad P_{\text {clay }} \cdot X+P_{\text {sand }} \cdot Y+P_{\text {silt }} \cdot Z= & 60 X+20 Y+20 Z \\ \text { Sand }= & 5 X+90 Y+5 Z \\ \text { Silt }= & 8 X+8 Y+84 Z\end{array}$

Assume that the three principal soil textures are clay $=A$, sand $=B$, and silt $=C$. Note that variable $A$ is the soil of clay, whereas $X$ is the clay component.

The solution becomes:

$X=A / 60-Y / 3-Z / 3$

$Y=B / 90-X / 18-Z / 18$

$Z=C / 84-2 X / 21-2 Y / 21$ 
Further, the solution of $X, Y$, and $Z$ as a function of $A, B$, and $C$ is

$X(A, B, C)=+94 A / 5375 \quad-19 B / 5375 \quad-17 C / 4300$

$Y(A, B, C)=-19 A / 21500+61 B / 5375-C / 2150$

$Z(A, B, C)=-17 A / 10750 \quad-4 B / 5375+53 C / 4300$

The soil thermal conductivity for any arbitrary soil texture, $k_{a r b}(\mathrm{~W} / \mathrm{mK})$, becomes

$$
\begin{aligned}
k_{\text {arb }} & =P_{\text {clay }} \cdot X+P_{\text {sand }} \cdot Y+P_{\text {silt }} \cdot Z \\
& =P_{\text {clay }} \cdot X(A, B, C)+P_{\text {sand }} \cdot Y(A, B, C)+P_{\text {silt }} \cdot Z(A, B, C)
\end{aligned}
$$

\section{Example:}

The thermal conductivity of clay loam, $\underline{k}_{\underline{c} \underline{2}_{2}}$ can be expressed as

$$
\begin{aligned}
\underline{k}_{\underline{c l}} & =P_{\text {clay }} \cdot X+P_{\text {sand }} \cdot Y+P_{\text {silt }} \cdot Z \\
& =35 \cdot X(A, B, C)+30 \cdot Y(A, B, C)+35 \cdot Z(A, B, C)
\end{aligned}
$$

where $A, B$, and $C$ must be calculated for each given step of moisture content, defined in Eq. (21). 